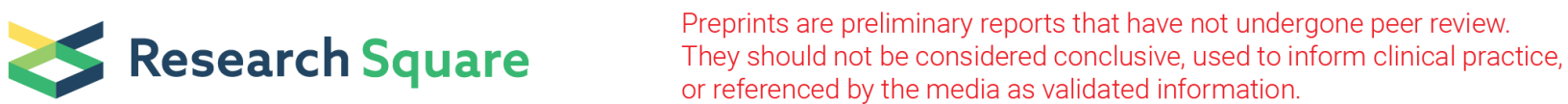

\section{Novel mitochondrial genes and gene reannotation: conservation of gene arrangements among available astigmatid mites}

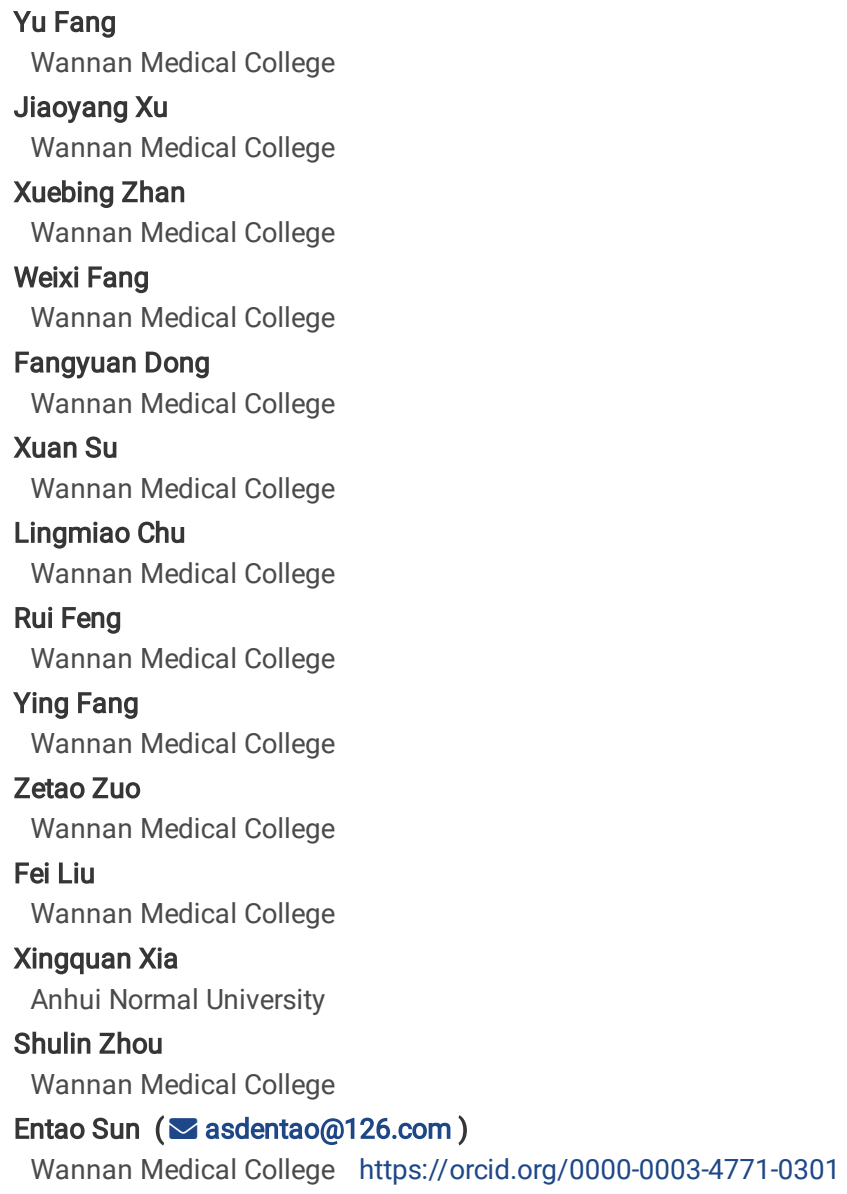

Research article

Keywords: Mitochondrial genome, Astigmatina, Glycyphagoidea, Gene rearrangement, tRNA structure, Largest non-coding region

Posted Date: December 1st, 2020

DOI: https://doi.org/10.21203/rs.3.rs-114352/v1

License: (a) (i) This work is licensed under a Creative Commons Attribution 4.0 International License. Read Full License 


\section{Abstract \\ Background}

Mitochondrial genomes (mitogenomes) of metazoans typically contain 37 genes, comprising 13 protein-coding genes, two rRNA genes, and 22 tRNA genes. To date, complete mitogenome sequences of 15 species of Astigmatina are available, and they present variation in a number of features, such as gene arrangements, tRNA unconventional secondary structures, and the number and internal structures of control regions. Furthermore, 11 astigmatid mites from six superfamilies share the same gene arrangement. Two available species from the genus Histiostoma reportedly have different mitochondrial (mt) tRNA gene arrangements.

\section{Results}

We sequenced the mitogenomes of Lepidoglyphus destructor and Gohieria fusca, both from the superfamily Glycyphagoidea (Astigmatina). In total, $37 \mathrm{mt}$ genes were identified in the two Glycyphagoidea species. Based on AT content and stem-loop structures, we divided the largest non-coding regions (LNRs) in L. destructor and G. fusca into two domains, respectively. The novel feature of two domains for the LNR was also found in Acalvolia sp. (Astigmatina, Hemisarcoptoidea). Using MITOS 2, tRNAScan, ARWEN, and manual approaches, we reannotated the mitogenomes of Histiostoma blomquisti, H. feroniarum, and Trouessartia rubecula. We reannotated six tRNA genes in $\mathrm{H}$. blomquisti and four tRNA genes in $\mathrm{H}$. feroniarum. We were able to identify all of the mt tRNA genes that were reported as lost in Tr. rubecula. The phylogenetic relationships found in our study were fairly consistent with previous studies of astigmatid mites phylogeny. Within Astigmatina, Glycyphagoidea was recovered as a monophyletic group.

\section{Conclusions}

A novel feature of the LNR was found in L. destructor, G. fusca and Acalvolia sp. (Astigmatina, Hemisarcoptoidea). This feature was not found in other available Astigmatina mitochondrial sequences. In the current study, most available astigmatid mitochondrial genomes shared the same consistent gene arrangement that could be the potential ancestral pattern in Astigmatina.

\section{Background}

Astigmatina (Astigmata, astigmatid) mites are economically and medically important pests that cause damage to stored food products [1] and trigger human allergies [2]. Glycyphagoidea mites belong to Acari, Acariformes, Astigmatina, which also are found in mattresses, pillows, and upholstery [3, 4].

Being derived from endosymbiotic a-Proteobacteria, complete mitogenomes have the usual characteristics of an entire genome, such as gene rearrangements [5], RNA secondary structures [6], and structural conservation of the non-coding regions [7]. Mitogenomes also supply information for phylogenetics, phylogeography, and population genetics [8-11]. Complete mitogenome sequences of Astigmatina have been reported for 15 species (as of October 9,2020$)$ from the six superfamilies: Acaroidea, Analgoidea, Hemisarcoptoidea, Histiostomatoidea, Pterolichoidea, and Sarcoptoidea. No complete mitogenome sequences from Glycyphagoidea, however, have been published in GenBank. To determine the types of gene rearrangements and to search for unique features in Glycyphagoidea, we sequenced and annotated the complete mitogenomes of Lepidoglyphus destructor(Schrank) and Gohieria fusca (Oudemans) (Sarcoptiformes, Glycyphagoidea).

The great majority of mitochondrial tRNAs in metazoans (>90\%) are predicted to share the canonical cloverleaf structure of tRNA sequences [12]. The conserved structure of tRNAs containing the $7 \mathrm{bp}$ acceptor stem, a $5 \mathrm{bp}$ anticodon stem and a D- and a T-arm have been characterized by tRNAscan-SE [13], ARWEN [14], and MITOS [15] in numerous research studies related to the analysis of insect tRNAs. Nevertheless, tRNAs that have lost either a D- or a T-arm (truncated tRNAs) are exceedingly common in sarcoptiform mites, possibly leading to the prediction of an implausible secondary structure or to the tRNA being missed during prediction.

In a previous study, two species from the genus Dermatophagoides had different tRNA gene arrangements [16]. After Klimov and O'Connor's reannotation of Dermatophagoides pteronyssinus, the two species were considered to share a consistent gene arrangement [17]. In Histiostoma, there are two available complete mitogenome sequences from the same genus, and the tRNA gene arrangements are different [18].

The presence of the full set of tRNA genes is universal, because tRNA genes are essential to the translation process [19]. In Sarcoptoidea, two tRNA genes (trnA and trnY) are absent from Sarcoptes scabiei. Xue et al. identified the two mt tRNA genes that were reported as lost in Sarcoptes scabiei through a manual approach [18]. In Acaroidea, three mt tRNA genes (trnF, trnS1, and trnQ) were reported as lost in Ty. longior [20] and Ty. Putrescentiae [21]. Fang et al. de novo sequenced and analyzed the mitochondrial genome of Ty. Putrescentiae, and identified the three tRNA genes that were reported as lost in a previous study [22]. In Analgoidea, five tRNA genes (trnA, $\operatorname{trnE}$, trnl, $\operatorname{trn} Y$, and $\operatorname{trn} V$ ) were reported absent from Trouessartia rubecula [23]. Nevertheless, this tRNA genes loss lacks convincing evidence.

The mitogenome gene arrangement of known astigmatid mites is rearranged compared with the hypothetical ancestor of the arthropods and shows several major rearrangements. Astigmatid mites' mitochondrial genomes usually exhibit conserved gene arrangements. Ten of the fifteen species share one gene arrangement that is supposed to reflect the possible common ancestor of astigmatid mites [11].

Thus, we reannotated the mitogenomes of $H$. blomquisti. $H$. feroniarum, and Tr. rubecula. Our goals were to (1) investigate whether tRNA gene arrangements really exist in the genus Histiostoma, (2) ascertain whether or not any tRNA genes really have been lost in Tr. rubecula, and (3) document mt gene 
rearrangements in the astigmatida investigated to date.

\section{Results}

\section{Mitochondrial genomes of Lepidoglyphus destructor and Gohieria fusca}

We determined the complete mitochondrial genomes of L. destructor (GenBank accession number: MT075728) and G. fusca (GenBank accession number: MN608156), with lengths of 14,663 bp and 14,741 bp, respectively. Both contained the typical set of 13 protein-coding genes (PCGs), 22 transfer RNAs (tRNAs), two ribosomal RNAs (rRNAs), and (Table 1). The overall base composition of the entire $L$. destructor mitogenome consisted of $25.0 \% \mathrm{~A}, 39.2 \% \mathrm{~T}$, $15.2 \%$ C, and $20.6 \%$ G. In G. fusca, the overall base composition of the entire mitogenome consisted of $25.8 \%$ A, 38.4\% T, $15.8 \%$, and $20.1 \%$ G. In both species, the nucleotide composition had the same AT bias (64.2\%). The combined protein-coding sequence lengths in the two species were 10,785 bp and $10,827 \mathrm{bp}$, respectively. In the $\mathrm{G}$. fusca mitogenome, 11 protein-coding genes used standard start codons known as ATN. In addition, several unorthodox initiation codons were used. Atp8 initiated with GTG, and nad3 started with codon TTG (Table 1). In L. destructor, 12 protein-coding genes used standard start codons, and nad3 starts with codon TTG (Table 1).

Table 1. Mitochondrial genome organization of Lepidoglyphus destructor and Gohieria fusca. Int = intergenic nucleotides; negative numbers indicate overlapping nucleotides between adjacent genes.

Mitogenomes of $L$. destructor and $G$. fusca have been predicted to have the full set of tRNA genes. The putative mt tRNA genes were highly truncated in both L. destructor (46 to $61 \mathrm{bp}$ ) and G. fusca (48 to $61 \mathrm{bp).} \mathrm{Only} \mathrm{trnK} \mathrm{showed} \mathrm{the} \mathrm{typical} \mathrm{cloverleaf} \mathrm{in} \mathrm{these} \mathrm{two} \mathrm{species} \mathrm{(Fig.} \mathrm{S1,} \mathrm{S2).} \mathrm{Other} \mathrm{tRNAs} \mathrm{showed} \mathrm{the}$ reduction of tRNA-D- and/or T-arms. In L. destructor, we identified 21 tRNAs using automated prediction. We determined the trnV manually by alignment with homologous sequences in other astigmatid mites based on their anticodon and secondary structure. In G. fusca, we identified 19 tRNA genes using automated prediction. We identified the other three tRNA genes $(\operatorname{trn} N$, $\operatorname{trn} V$, and $\operatorname{trn} A)$ manually.

\section{The novel feature of the largest non-coding region}

Two large (>50 bp) non-coding regions (NCRs) could be identified in the L. destructor and G. fusca mitogenomes (Table 2). In L. destructor, the largest noncoding region (LNR, $813 \mathrm{bp}$ ) had an overall AT content of $68.4 \%$ and could be divided into two domains, domain I (463 bp) and domain II (350 bp), based on AT content and stem-loop structures (Fig. 1A). Domain I was on the J-strand at the $3^{\prime}$ end of trnF and had an AT content of $62.2 \%$. A peculiar feature of this domain is the presence of a stem-loop structure with a length of 432 bp and short sequences (5'-GGGGGTAGGGG and CCCCTACCCCC-3') (Fig. 1A I-box). Domain II was on the J-strand at the $5^{\prime}$ end of the trnS1 gene. The AT content was $78.9 \%$, which was more AT-rich than domain I. Comparative sequence analysis of this domain identified conserved sequences, one microsatellite-like AT-repeat element, and several stem-loop structures (Fig. 1). In the mitochondrial genome of $G$. fusca, the LNR was 861 bp long and had an overall AT content of $70.7 \%$. The LNR also could be divided into two domains. Domain I had a stem loop structure with a length of 435 bp (Fig. 1A). The short sequences (5'-GGGGGTAGGGG and CCCCTACCCCC-3') were not found in domain I. The AT contents of domain I and domain II were $57.3 \%$ and $86.6 \%$, respectively. The conserved sequences, one microsatellite-like AT-repeat element, and several stem-loop structures, were found in domain II. In total, we found the feature of two domains in both species from Glycyphagoidea.

Fig. 1. Conserved sequence blocks and secondary structures of the largest non-coding region in astigmatid mites. (A) Mapped on L. destructor, G. fusca, and Acalvolia sp. The domain I (striped box) and domain II (white box) are marked. The conserved sequences in domain I and the conserved palindromic sequences in domain II are shown in underlined letters. The A+T content of two domains is indicated. (B) Mapped on Aleuroglyphus ovatus, Caloglyphus berlesei, Rhizoglyphus robini, Tyrophagusputrescentiae, Dermatophagoides pteronyssinus,D. farinae, Psoroptes cuniculi, Ardeacarus ardeae, Carpoglyphus lactis, Sarcoptes scabiei, and Trouessartia rubecula (after revision). The conserved palindromic sequences are shown in underlined letters. Accession numbers of the analyzed sequences are reported in Table 6.

To investigate whether the feature of two domains existed in other astigmatid mites, we conducted a comparative analysis of non-coding regions from all available Astigmatid mitogenomes (Table 2). In astigmatid mites, most reported mitogenomes feature a compact structure that usually contains two conserved site-specific NCRs (except for Ty. longior, H. blomquisti, and H. feroniarum) and several nonconserved NCRs. These conserved site-specific NCRs are located between trnF-trnS1 and trnW-nad1 with high AT content (the average content is $84.8 .0 \%$ and $71.9 \%$, respectively). The LNR is usually located in trnF-trnS1, and the length of this region averages $420 \mathrm{bp}$. The three longest conserved NCRs are in L. destructor, G. fusca, and Acalvolia sp. (813, 861 , and 753 bp, respectively). The shortest NCRs located in trnF-trnS1 is only 76 bp in Sarcoptes scabiei.

Table 2. Distribution of NCRs in the astigmatid mites mitochondrial genomes.

Note: Non-coding regions marked with a star are assumed to be putative control regions. The data for Trouessartia rubecula, Histiostoma blomquisti, and $H$. feroniarum in the table are after our revision.

Note that the several conserved sequences in domain II of L. destructor and G. fusca, including microsatellite-like (AT)n and several hypothetical stem-loop structures, were observed in the NCRs between trnF-trnS1 for most reported astigmatid mitogenomes (Fig. 1B). These conserved sequences were reported in the LNRs for Acaroidea species (Aleuroglyphus ovatus, Caloglyphus berlesei, Rhizoglyphus robini, and Tyrophagusputrescentiae), Pyroglyphidae species (Dermatophagoides pteronyssinus and D. farinae), Hemisarcoptoidea species (Acalvolia sp., Carpoglyphus lactis), and Sarcoptoidea (Psoroptes cuniculi) [22, 24-26]. In addition, we also found these conserved sequences in Pterolichoidea (Ardeacarus ardeae). Additionally, we observed microsatellite-like (AT)n sequence in the LNR in Sarcoptoidea (Sarcoptes scabiei) and Analgoidea (Trouessartia rubecula). 
The other conservative non-coding region was located in trnW-nad1, and the length of this region averaged 72 bp (Table 2). The longest reached 273 bp in Acalvolia sp.. The shortest was in Ardeacarus ardeae, with only 29 bp. A similar sequence $\left[5^{\prime}-(\mathrm{G})_{n} T A(G)_{n}-3^{\prime}\right]$ was found in the NCR of most available astigmatid mites (including the Tr. rubecula and the $H$. feroniarum after reannotation), except for Ardeacarus ardeae. A similar sequence [5'-(G)nTA(G)n - $\left.3^{\prime}\right]$ also was found in domain I of the LNR for L. destructor and Acalvolia sp., except domain I of the LNR for G. fusca. This sequence, [5'-(G)nTA(G)n -3'], seemed to be conserved in most available astigmatid mites.

Additionally, some astigmatid mites also exhibited other nonconservative NCRs (Table 2). Both $H$. blomquisti and $H$. feroniarum had one nonconservative NCR, and several stem-loop structures were found in these NCRs. The sequences and the stem-loop structures did not seem to be conserved.

Compared with the other described astigmatid mite NCRs, only Acalvolia sp. (Astigmata, Hemisarcoptoidea) showed a similar feature of two domains in the LNR. In Acalvolia sp.,the LNR also could be divided into two domains: a 469 bp fragment of domain I and a 284 bp fragment of domain II. The AT contents of domain I and domain II were $71.6 \%$ and $84.9 \%$, respectively. In domain I, we found short sequences (5'-GGGGGTAGGGG and CCCCTACCCCC-3') and a stemloop structure. The conserved sequences among astigmatid mites were found in domain II (Fig. 1A).

As described earlier, the feature of two domains for the LNR was found only in L. destructor, G. fusca, and Acalvolia sp. among all available astigmatid mites.

\section{Reannotation of four tRNA genes for Histiostoma blomquisti}

In terms of previous study for $\mathrm{H}$. blomquisti, the smallest four tRNAs (trnA, trnS2, trnR, and trnV) could only be annotated manually, but the remaining tRNAs ( $\operatorname{trn} C, \operatorname{trnF}$, and the other $16 \mathrm{tRNAs}$ ) were identified using more than a manual approach [27]. To find more probable structures, we reannotated four tRNAs ( $\operatorname{trn} C, \operatorname{trn} A, \operatorname{trn} F$, and $\operatorname{trnS} 2$ ) based on the mitogenome from our analysis. We identified $\operatorname{trn} F$ and $\operatorname{trnS} 2$ manually, and verified $\operatorname{trn} C$ and $\operatorname{trn} A$ based on the minimum free energy (MFE).

Our trnF identified by manual sequence alignment was more conservative, showing fewer mismatches in the acceptor stem. This tRNA lies on the J-strand at the 3' end of nad5. Without predictions from tRNA search programs, we manually retrieved a tentative trnS2 from the sequence of previous study [27].

Similarly, we manually inferred the putative trnS2 to be a D-loop with fewer mismatches on stems. As a common phenomenon in Astigmatina, this D-loop was extremely truncated (43 bp). Compared with $\mathrm{H}$. feroniarum and other astigmatid species, trnS2 in our study was more conserved (Table 3).

Table 3. The alignment of nucleotide sequences of four mitochondrial tRNA genes

(trnS2, trnW, trnF, and trnl) in five reported astigmatid species in four different superfamilies.

Whenever contradictory predictions occurred, we calculated the minimum free energy (MFE) as a proxy. According to the MFE, we determined trnC and trnA in our study. These were more probable as having fewer mismatches on stems and arms (Fig. 2). After being amended, trnC apparently shared $54 \mathrm{bp}$ nucleotides with the adjacent $t r n P$, these two genes overlapped and were on opposite strands (Table S1).

Fig. 2 Secondary structures of $\operatorname{trn} C$ and $\operatorname{trn} A$ for Histiostoma blomquisti and $\operatorname{trn} C$, trnV, and trnQ for Histiostoma feroniarum in our study.

Note: Bars indicate Watson-Crick base pairings; dots and circles represent GU pairs and mismatched pairs, respectively. ${ }^{*} \mathrm{Hb}$ and * $\mathrm{Hf}$ are obtained in this study. MFE indicated the minimum free energy value.

Because of the trnF occupancy, the boundaries of nad5 in H. blomquisti changed. Due to the tRNA reannotation, the NCRs also were changed. In a previous study, the NCRs were located in rrnS-trnV, trnF-trnA. After the revision, one conserved site-specific NCR was identified between trnF-trnS1, with high AT content. The other NCR was still located in rrnS-trnV, with the length increased to $1598 \mathrm{bp}$ (Table 2).

\section{Reannotation of six tRNA genes for Histiostoma feroniarum}

In previous work, 16 of 22 tRNA genes ( $\operatorname{trn} C, \operatorname{trn} V, \operatorname{trn} Q, \operatorname{trn} F, \operatorname{trn} W, \operatorname{trn}$, and 10 other tRNAs) were predicted using tRNA programs; the other six were identified manually [18].

In this study, we used manual annotation to reannotate $t r n F$, $t r n W$, and $t r n /$ of $H$. feroniarum. Our trnF for $H$. feroniarum was identified by manual alignment and was conserved with the reannotated $t r n F$ in $H$. blomquisti (Table 3). In our analysis, trn W was reannotated by sequence alignment. This sequence also had fewer mismatches (Table 3). In the previous study, the D-loop trn/ with the less common anticodon sequence AAU was reported in $H$. feroniarum [18], but D-loop trn/ had never been reported in other Astigmatina. Our trn/ was reannotated manually based on anticodon sequences and secondary structures. In our study, we also observed the less common anticodon sequence AAU. We inferred this reannotated trn/ to be a TV-loop structure. This sequence was aligned to H. blomquisti but was the only other remaining member of Histiostomatoidea. The reannotated trn/ presented considerable similarity (Table 3 ).

To select the most probable tRNAs, minimum free energy (MFE) was calculated for three tRNA genes ( $\operatorname{trnC}, \operatorname{trn} V, \operatorname{trn} Q$ ). We found smaller MFE values than in previous annotations. In our study, $\operatorname{trn} C$ was retrieved between $\operatorname{trn} S 2$ and $\operatorname{trn} P$, and $\operatorname{trn} V$ was retrieved between $12 S$ and $16 S$, whereas the positions were coincidentally the opposite from those predicted by Xue et al. [18]. Our trnC had common anticodon sequences GCA among astigmatid mites, whereas the previously described $t r n C$ used ACA instead of GCA in anticodon sequences. When we calculated MFE, both $\operatorname{trnC}$ and $t r n V$ in our study were more thermodynamically stable (Fig. 2). After reannotation, the $\operatorname{trn} V$ had 52 bp overlapping with the contiguous $r$ rnS on the same chain. Notably, the previously described trnQ was annotated on the J-strand at the $3^{\prime}$ end of nad5 [18], but many mismatches on stems and arms were found in this position. In fact, most nucleotides of $\operatorname{trn} Q$ among Astigmatina were highly conserved, and when located on the N-strand downstream of trnS1, the reannotated trnQ had a smaller MFE. 
After amendment of the tRNA genes, the boundaries of nad2 of $H$. feroniarum changed because of trn/ occupancy. We also observed changes to the rrn $L$ size of $H$. feroniarum on account of trnW occupancy (Table S1). With alignment by Clustal W 2.0, the rrnL boundaries of the two Histiostoma species were more conserved. In addition, we changed one position of the NCR because of the reannotation of trnWand trnl. After the revision, we could identify one conserved site-specific NCR with high AT content between trnWand nad1.

Notably, the reannotations of $\mathrm{H}$. blomquisti and $\mathrm{H}$. feroniarum mitogenomes led to the mtDNA gene order for both Histiostoma species sharing the gene arrangement of a possible common ancestor of astigmatid mites, excluding the different locations of non-coding regions (Fig. 3 ).

Fig. 3. Mitochondrial gene arrangements in the sarcoptiform mites. The arrow pointing to the right represents the (+)-strand, and the arrow to the left the (-)strand. Translocated or inverted genes are color-coded (green: inversion and translocation; pink: translocation; yellow: inversion). rRNA genes are in blue. The possible common ancestor among astigmatid mites is found in different genera and families. Species marked with a star: tRNAs reannotated in our study. Species marked with a triangle: the gene order in previous studies.

\section{Retrieving the "lost" mt tRNA genes in Trouessartia rubecula}

In Trouessartia rubecula, Esteban et al. predicted tRNAs based solely on the MITOS WebServer, and five tRNA genes (trnA, $\operatorname{trn} E$, $\operatorname{trn} l, \operatorname{trn} Y$, and $\operatorname{trn} V$ ) were not identified [23]. In protein annotation, the common start codon is ATN, but the cox 1 gene start codon of T. rubecula is the uncommon TCT. T. Rubecula was reported to contain three D-loop sequences. The lengths of these non-coding regions are abnormally short, and the location of these region is different from the common non-coding regions.

In the current study, we used tRNAscan-SE, ARWEN, and MITOS 2 to predict the missing $\operatorname{trnE}$, $\operatorname{trn}$, and $\operatorname{trn} Y$, and we annotated trnA and trnV using manual comparison. The secondary structure with the smallest constrained MFE was considered to be the most likely one (Fig. 4). We verified the tRNA genes of the two sarcoptiform mites by comparison of secondary structures and conserved nucleotide sequences with several Astigmatina species (Table 4). Nucleotides that pair at the arms (acceptor arm, D arm, anticodon arm, and T arm) are underlined in the figure. We analyzed the codon usage in the mt protein-coding genes of the 17 species of astigmatid mites to see whether and how the corresponding codons of the "lost" tRNA genes were used. Overall, the codon use was similar between Tr. rubecula and other astigmatid mites (Fig. 5).

Note: Bars indicate Watson Crick base pairings; dots and circles represent GU pairs and mismatched pairs, respectively. MFE indicated the minimum free energy value.

Table 4 The alignment of nucleotide sequences of two mitochondrial tRNA genes ( $\operatorname{trn} A$ and $\operatorname{trn} V$ ) in six species: Conserved nucleotides are shaded in gray across these five mites.

Note: Nucleotides that pair at the arms (acceptor arm, D arm, anticodon arm, and T arm) are underlined. Sequences of anticodons are in boldface. Aleuroglyphus ovatus (Ao), Caloglyphus berlesei (Cb), Rhizoglyphus robini (Rr), Dermatophagoides farinae (Df), Ardeacarus ardeae (AA), and Trouessartia rubecula (TR) in our study.

Fig. 5 Relative synonymous codon usage (RSCU) and codon numbers of 22 amino acids (a, c, d, e, f, g, h, i, k, I1, I2, m, n, p, q, r, s1, s2, t, v, w, and y) in the mitochondrial $(\mathrm{mt})$ genomes of astigmatid mites. The X-axis indicates the astigmatid mites; the Y-axis indicates the RSCU or total number of codons. The blue column indicates the codons that are complimentary to the anticodons of their corresponding mt tRNA. The red, green and purple columns indicate the imperfect, synonymous codons to the anticodons of their corresponding mt tRNA genes.

After revision, we reannotated the position of the cox 1 gene. The reannotated cox 1 gene had a length of 1536 bp and had ATA as the initiation codon rather than the uncommon start codon TCT identified in a previous study. The result from BLASTn supported our boundaries for cox1. The LNR (301 bp in length) was arranged in the same way as most LNRs in the available sequences for astigmatid mites.

\section{New insight into astigmatid mitochondrial gene arrangement}

Compared with Limulus polyphemus as the hypothetical ancestor of arthropods, gene orders were rearranged in the mitogenomes of 17 astigmatid mites (Fig. 3). We found that the mitogenomes of 13 astigmatid mites from six superfamilies (Glycyphagoidea, Acaroidea, Analgoidea, Sarcoptoidea, Pterolichoidea, and Hemisarcoptoidea) shared a consistent gene order, indicating that this gene arrangement was from the possible common ancestor of astigmatid mites. The mitogenomes of Histiostoma blomquisti, Histiostoma feroniarum, and Acalvolia sp. represented three types of gene arrangements resulting from the different locations of the non-coding regions from the gene arrangement of the possible common ancestor of astigmatid mites (Fig 3). The mt gene order of Tyrophagus longior was rearranged compared with other astigmatid mites because of tRNA loss.

\section{Phylogenetic analysis}

We constructed a phylogenetic tree based on a nucleotide data set from $13 \mathrm{mt} \mathrm{PCGs} \mathrm{of} 17$ astigmatid mites. The ML and BI analyses showed fully consistent topologies, and we provided the percentage of the bootstrap support at each node. The phylogenetic tree showed that the monophyly of Glycyphagoidea recovered with strong support (BPP $=1$ and $\mathrm{BSP}=100 \%$ ), as well as the monophyly of Acaroidea, Hemisarcoptoidea, and Histiostomatoidea (Fig. 6 ). The monophyly of two superfamilies, Analgoidea and Sarcoptoidea, was always rejected. The logical next steps would be the integration of more astigmatina mitogenomes, including species from each of the six superfamilies.

Fig. 6 Phylogenetic tree inferred from mitochondrial genome sequences using maximum likelihood and Bayesian methods. Branch lengths presented here follow the Bayesian methods analysis. Node numbers indicate Bayesian posterior probabilities (BPP) and maximum likelihood bootstrap proportions (BSP). * 
indicates clades with BSP $<70 \%$.

\section{Discussion}

For the first time, we determined the complete $L$. destructor and G. fusca mitogenomes in the superfamily Glycyphagoidea. Like most astigmatid mites, we identified 37 mitochondrial genes and one CR in the two Glycyphagoidea species. For comparison, the 15 other species of Astigmatina with complete mitochondrial genomes available in GenBank exhibited an average genome size of 14,227 bp with high AT content. These values closely agreed with those we observed for both Glycyphagoidea species. The length variation of mitogenomes was usually due to length variation in the LNRs [28].

The LNRs in the mitochondrial genomes were less conserved than the coding genes, and they have not been well studied compared with other mitochondrial genes [29]. Astigmatid mites have two conservative non-coding regions and several nonconservative non-coding regions. The LNRs were usually located in trnF-trnS1, and several conserved sequences were found in the regions, including one microsatellite-like (AT)n element and several stem-loop structures. The conserved sequences were common and present in 12 astigmatid mites, including $L$. destructor and $G$. fusca, and these sequences were involved in the regulation of mitogenome replication [30].

In addition to abovementioned features, in L. destructor and G. fusca, based on AT content and hypothetical stem-loop structures, we divided the LNR into two domains and identified several conserved features in both species. Domain II was more AT-rich than domain I. Similar LNR features have not been reported for other Acari. A comparison of the LNR with available Astigmata mitochondrial sequences showed that similar unusual features of the LNR could be found only in Acalvolia sp. (Hemisarcoptoidea). Whether this LNR feature is general needs to be investigated by sequencing of additional Astigmata mitogenomes.

Truncated tRNAs have been found in all published mitogenomes of Acariformes [11, 12]. In addition, mismatches in the stems occur regularly in astigmatid mites. Both such tRNAs pose challenges for tRNA prediction programs [31]. In previous studies with two species of the genus Histiostoma, tRNA gene arrangements were different from each other. In Tr. rubecula, five tRNAs were reported to be lost. In the current study, we reannotated the mitogenomes of $H$. blomquisti, H. feroniarum, and Tr. rubecula. In Histiostoma, in addition to prediction programs, we used manual annotation by sequence comparison when alternative anticodons were considered [18]. We reannotated $\operatorname{trn} C, \operatorname{trn} A, \operatorname{trn} F$, and $\operatorname{trn} S 2$ in $H$. blomquisti, and $\operatorname{trn} C, \operatorname{trn} V, \operatorname{trn} Q, \operatorname{trn} F, \operatorname{trn} W$, and $\operatorname{trn} /$ in $H$. feroniarum. The reannotation of $\operatorname{trn} F(H$. blomquisti) was based on a comparison among astigmatid mites. The $\operatorname{trnS} 2(H$. blomquisti) and the $\operatorname{trn} F$ and $\operatorname{trn} W(H$. feroniarum) were identified by alignment with the tRNA of the only other species in the same genus. The trn/ was reannotated to have a TV-loop, which was a more conserved secondary structure than the D-loop of $t r n /$ identified previously. The D-loop of trn/was extremely rare in Astigmatina, only known in $H$. feroniarum [18]. We used the MFE to verify $\operatorname{trn} C$ and $\operatorname{trn} A$ (H. blomquisti) and $\operatorname{trn} C$, $\operatorname{trn} V$, and $\operatorname{trn} Q$ ( $H$. feroniarum). Compared with the $\operatorname{trn} C$ from a previous study, our $\operatorname{trnC}(H$. feroniarum) had the common anticodon among astigmatid mites. In conclusion, the tRNAs after our reannotation contained more conserved sequences among homologues in species of Histiostoma or Astigmatina, and had more stable secondary structures than previously identified. Among these manually retrieved tRNAs, the extreme situations were found in trnC of $H$. blomquisti and trnV of $H$. feroniarum. The genes overlapped between $\operatorname{trnC}$-trnP on the opposite strand; thus, the transcripts did not overlap [32]. The overlap between trnV-rrnS in $H$. feroniarum was on the same chain. Sequence overlaps universally existed in astigmatid species and may be corrected later through post-transcriptional editing, alternate treatment, and relaxed restrictions on tRNA structure $[33,34]$. Whether the consistent gene arrangement for Histiostoma is general needs to be investigated by sequencing additional Histiostomatoidea mitogenomes.

After the revision, the Tr. rubecula had a full set of tRNAs. Codons for all 22 amino acids were present in the protein-coding genes in all astigmatid mites. No evidence has yet indicated that nuclear tRNA genes can be imported into mitochondria in mites or other animals [19]. If an mt tRNA gene is indeed lost and there is no nuclear replacement, then its corresponding codons in the mt protein-coding genes will not be translated. Thus, the "loss" of mt tRNAs may not exist in astigmatid mites. Rearranged gene orders in the mitogenomes not only can provide phylogenetic information but also are useful in resolving the phylogeny of insects $[35,36]$. Therefore, the correct annotation of genes is important for phylogenetic and evolutionary studies. Our study had four types of gene arrangements in Astigmatina. The mitogenomes of 13 astigmatid mites from six superfamilies shared one type of gene rearrangement. This gene rearrangement likely was the most conserved gene arrangement among the astigmatid mites. In addition, these four types of gene arrangements for 37 genes (13 PCGs, 22 tRNAs, and 2 rRNAs) were consistent. The gene arrangement of Ty. longior represented a unique type because of missing tRNAs [20]. Two species had complete mitogenomes reported in the genus Tyrophagus. The gene arrangement of Ty. putrescentiae was consistent with the possible common ancestor of astigmatid mites [22]. Murillo et al. used COI to analyze molecular phylogenetics and suspected that a misidentification existed in the Ty. longior [20] sequence, as it clustered with other sequences of Ty. putrescentiae [36]. Hence, our results did not support the loss of mt tRNA genes in these astigmatid mites. Our results did support the hypothesis that the conserved gene arrangement in most available species was likely the arrangement of the possible common ancestor of astigmatid mites [11].

Within the Astigmatina, we observed the monophyly of Glycyphagoidea, Hemisarcoptoidea, Acaroidea, and Histiostomatoidea. Consistent with a previous study, the monophyly of two superfamilies, Sarcoptoidea and Analgoidea, was rejected [11, 23, 31]. Our finding supported the suggestion that the phylogeny of Astigmata is far from resolved at the superfamily level [11, 38, 39].

\section{Conclusion}

In this study, we determined the complete L. destructorand G. fusca mitogenomes. A novel feature of the LNR was found in L. destructor, G. fusca, and Acalvolia sp., the feature that was not found in other available Astigmatina mitochondrial sequences. We reannotated the mitogenomes of $T$ r. rubecula, $H$. blomquisti, and $\mathrm{H}$. feroniarum. The gene order of 13 astigmatid mites from six superfamilies shared the gene order that was identical to the possible common ancestor of astigmatid mites. This information from our study has important ramifications for our understanding of mitogenome evolution in astigmatid mites. 


\section{Methods}

\section{Mite collection and DNA extraction}

We collected samples of Gohieria fusca from a flour factory in Wuhu, southeast China, in July 2016. We collected samples of $L$. destructorfrom a flour shop in Wuhu in spring 2018. L. destructor and G. fusca were reared at $25^{\circ} \mathrm{C}$ and $85 \%$ relative humidity in the dark using the following medium: wheat germ, corn flour, and baker's yeast at a ratio of 10:10:1 by weight [40]. Mites were stored in $100 \%$ ethanol at $-20^{\circ} \mathrm{C}$ until use. We identified specimens based on their morphological characteristics [41]. The cox1 sequences of L. destructorand Gohieria fusca were obtained with the primers LWCOI_U and LWCOI_L, as suggested by Webster et al. [42]. After performing BLASTn searches of the nucleotide collection (nr/nt) database of the NCBI, the results showed that the cox1 sequence from two specimen were very similar to several sequences from L. destructor and Gohieria fusca. In L. destructor, the identities were $98.91 \%$ (accession number: EU078972) and 98.64\% (accession number: AY525569). In G. fusca, the identities were 98.64\% (accession number: MG279724) and 98.38\% (accession number: MG279719). Therefore, the two specimens collected in the current study were identified as L. destructor and G. fusca. We extracted whole-genomic DNA by standard phenol-chloroform extraction [43].

\section{Sequence assembly, annotation, and analysis}

We obtained the mitogenomes of L. destructor and G. fusca by the Shanghai Majorbio Bio-pharm Biotechnology Company (Shanghai, China) and Shanghai BIOZERON Company (Shanghai, China), respectively. Both were sequenced with an Illumina HiSeq sequencer [44]. We annotated the assembled genomes using the MITOS WebServer [15] using the mitochondrial invertebrate genetic code for invertebrates. We calculated relative synonymous codon usage and amino acid frequencies using MEGA X [45]. The PCGs boundaries were confirmed manually in MEGA X software and BLASTp searches conducted at the NCBI website [46]. We identified secondary structures of the LNR using the Mfold web server [47]. The two rRNA genes, $r r n L$ and $r r n S$, were curated by BLAST searches based on sequence similarity. The boundaries of rRNAs were assumed to be immediately after their upstream genes and before their downstream genes [18]. To predict tRNAs, we used tRNAscan-SE [13], ARWEN [14], MITOS, and MITOS2 [15]. The tRNAs that could not be predicted by programs were determined manually by alignment with their homologues in other astigmatid mites [11]. We also used the manual comparative approach to determine the results of tRNA search programs.

\section{The largest non-coding region of mitogenomes amplification and sequencing}

To verify the number of variable length AT-repeats in the LNR, we extracted DNA from 10 individual mite offspring from a single female using the DNeasy Blood and Tissue Kit (QIAGEN, Hilden, Germany). According to the obtained sequences, we designed specific polymerase chain reaction (PCR) primers for each species (Table 5) to amplify the remaining genome by long PCR as a single fragment using the manufacturer's rapid PCR protocol.

We amplified the LNRs for $G$. fusca and $L$. destructor using four flanking primers. The primer specifications and the length of each amplified fragment are given in Table 5. We used prime STAR GXL DNA polymerase (Takara) for PCR under the following cycling conditions: 30 cycles of $98^{\circ} \mathrm{C}$ for $10 \mathrm{~s}, 52^{\circ} \mathrm{C}$ for $16 \mathrm{~s}$,

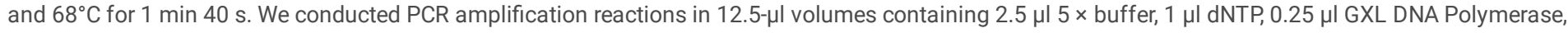
$0.25 \mu \mathrm{l}$ of each primer, $0.5 \mu \mathrm{l}$ of template DNA, and double-distilled water to a final volume of $12.5 \mu \mathrm{l}$. Finally, PCR products were separated by electrophoresis on a 1\% agarose gel. PCR products were purified with a QIAquick Spin PCR Purification Kit (Qiagen). PCR products were cloned into a Blunting Kination Ligation Kit (BKL) (Takara). After heat-shock transformation of Escherichia coli (DH5a cells), we aligned their similarity against the sequence by using Clustal W $2.0[48]$

Table 5 The primers used for the amplification of Gohieria fusca and Lepidoglyphus destructor mitochondrial genomes, with the size of each fragment that was amplified in bp.

\section{The reannotations of Histiostoma blomquisti, H. feroniarum, and Trouessartia Rubecula mitogenomes}

The assembled genome was annotated using the MITOS WebServer [15]. The boundaries of PCGs were confirmed manually by MEGA X version 10.1.5 [45] software and BLASTp searches conducted in the NCBI database [46]. Based on highly conserved sequence motifs, $r r n L$ and $r r n S$ were identified by BLASTn searches of the NCBI database. To predict tRNAs, we used tRNAscan-SE [13], ARWEN [14], and MITOS 2. The tRNA genes that could not be identified by the tRNAscan-SE, ARWEN, and MITOS 2 were determined manually by alignment with their homologues in related species in the Astigmatid mites based on their anticodon and secondary structures [11]. If a tRNA can not be determined by automated prediction or manual comparative approach, such as predictions of the different tools were in some cases contradictory, the Mfold Server [47] and RNAeval (ViennaRNA package v.2.3.3)[49] were used for calculating the minimum free energy (MFE) to select the most probable among alternative structures (constrained analysis). The secondary structure with the smallest constrained MFE was considered as the most stable one [6]. We also used the manual comparative approach to determine the results of tRNA prediction programs.

\section{Phylogenetic analysis}

To infer the phylogenetic positions of L. destructor and G. fusca within the Astigmata, we generated a dataset of 19 mite taxa (17 astigmatid mites and two oribatid mites) (Table 6) that included only those species with a complete set of 13 PCGs. First, the nucleotide sequences of each PCG was translated under the invertebrate $\mathrm{mt}$ genetic code. Then the amino acid sequences of 13 PCGs were aligned individually by MAFFT v7 [50]. Additionally, large gaps and ambiguous sites were deleted by Gblocks v.0.91b [51]. Finally, we conducted phylogenetic analyses using maximum likelihood (ML) and Bayesian inference (BI) methods.

Table 6. Mitochondrial genomes employed in this study. 
We analyzed the dataset of amino acid sequences of 13 PCGs as two types of matrices: combined algorithm and partitioned algorithm. Dataset partitioning was performed by PartitionFinder v.2.1.1 [52] based on an initial total of 13 data blocks (amino acid sequences, 13 protein-coding genes). We predicted the models by PartitionFinder using the Akaike information criterion (AICC). PartitionFinder used unlinked branch lengths, and the greedy search algorithm was used for amino acid sequences and the MrBayes model. For the dataset of partitioned amino acid sequences based on genes, two substitution models [GTR+I+G (COI, COII, ATP6, NAD3, NAD1, NAD2, NAD4, NAD4L, NAD5, NAD6, CYTB), GTR+G (ATP8, COIII)] were chosen by PartitionFinder. For the dataset of combined amino acid sequences, the substitution model GTR+I+G was chosen by PartitionFinder.

For the dataset of amino acid sequences, we performed BI analyses with MrBayes v.3.2.2 [53]. For MrBayes v.3.2.2, we used separate data partitions plus mixed models and conducted two independent runs each with four Markov chain Monte Carlo runs (one cold chain and three heated chains). The two datasets were run for 2 million generations, with trees sampled every 1000 generations. We then applied a conservative burn-in of $25 \%$. We evaluated the convergence of the parameter estimates with TRACER v.1.6. All estimated parameters showed ESS values above 200. We edited the consensus tree with FigTree v.1.4.0. Nodes supported by Bayesian posterior probabilities (BPP) $\geq 95 \%$ were considered strongly supported [54]. We performed ML analyses on the combined and partitioned datasets using the GTRGAMMAI model in the RAXML-7.0.3-WIN [55]. We assessed clade support using a nonparametric bootstrap with 1000 replicates. We considered nodes supported by bootstrap values (BSP) $\geq 70 \%$ to be strongly supported [56].

\section{Abbreviations}

atp6 and atp8: Genes for ATP synthase subunits 6 and 8; bp: Base pair; cob: Gene for cytochrome b; cox1, cox2, and cox3: Genes for cytochrome coxidase subunits 1, 2 and 3; CR: Control region; DNA: Deoxyribonucleic acid; mitogenome: Mitochondrial genomes; Int: intergenic nucleotides; LNRs: Largest noncoding regions; nad1, nad2, nad3, nad4, nad4L, nad5, and nad6: Mitochondrial genes for NADH dehydrogenase subunits 1-6 and 4 L; NCRs: Non-coding regions; PCGs: Protein-coding genes; PCR: Polymerase chain reaction; rRNA: Ribosomal RNA; rrnS and rrnL: Genes for small and large subunits of ribosomal RNA; RSCU: Relative Synonymous Codon Usage; trnA: tRNA gene for alanine; tRNA: Transfer RNA; trnC. tRNA gene for cysteine; trnD: tRNA gene for aspartic acid; trnE: tRNA gene for glutamic acid; trnF: tRNA gene for phenylalanine; trnG: tRNA gene for glycine; trnH: tRNA gene for histidine; trnl: tRNA gene for isoleucine; $\operatorname{trnK}$ : tRNA gene for lysine; $\operatorname{trn} L$ 1: tRNA gene for leucine; $\operatorname{trn} L 2$ : tRNA gene for leucine; trnM: tRNA gene for methionine; trnN: tRNA gene for asparagine; $t r n P$. tRNA gene for proline; $\operatorname{trn} Q$ : tRNA gene for glutamine; $\operatorname{trnR}$ : tRNA gene for arginine; trnS1: tRNA gene for serine; trnS2: tRNA gene for serine; $\operatorname{trnT}$ : tRNA gene for threonine; $\operatorname{trn} V$ : tRNA gene for valine; trnW: tRNA gene for tryptophan; $\operatorname{trn} Y$ : tRNA gene for tyrosine; $\mu$ l: Microliter.

\section{Declarations}

\section{Ethics approval and consent to participate}

No specific permits were required for the mites collected for this study in China. The mite specimens were collected from mushrooms, and the field studies did not involve endangered or protected species. The species in our study are common mites and are not included in the "List of Protected Animals in China".

\section{Consent for publication}

Not applicable.

\section{Competing interests}

The authors declare that they have no competing interests.

\section{Funding}

This work was supported by the Natural science Foundation of China (No. 31870352), Anhui Provincial Natural Science Foundation [Grant No.1708085QH187], and the Youth Talent Support of Wannan Medical College (No. wyqnyx201902). The founding bodies had no role in the design of the study and collection, analysis, and interpretation of data and in writing the manuscript.

\section{Availability of data and materials}

The datasets generated and/or analysed during the current study are not publicly available due [the mt genomes of Lepidoglyphus destructorand Gohieria fusca submitted on GenBank under the accession numbers MT075728 and MN608156, and not released yet] but are available from the corresponding author on reasonable request.

\section{Authors' contributions}

SET, XXQ, ZSL, and FYu designed the study. FYu, XJY, ZXB performed the laboratory work. FYu, XJY, SX, CLM, FR, and FYing analyzed the data. FYu, XJY, ZXB, FWX, DFY, and ZZT contributed to draft writing and literature search. SET, ZSL, XXQ, and LF reviewed and revised the manuscript. All authors read and approved the final manuscript

\section{Acknowledgments}

We thank LetPub (www.letpub.com) for its linguistic assistance during the preparation of this manuscript.

\section{Author details}


1 Department of Health Inspection and Quarantine, Wannan Medical College, Wuhu 241002, China.

2 Department of Medical Parasitology, Wannan Medical College, Wuhu, China.

${ }^{3}$ College of Life Science, the Provincial Key Lab of the Conservation and Exploitation Research of Biological Resources in Anhui, Anhui Normal University, Wuhu, China.

\section{References}

1. Cui YB. When mites attack: domestic mites are not just allergens. Parasites Vectors. 2014;7:411. doi:10.1186/1756-3305-7-411.

2. Fraser TA, Shao R, Fountain-Jones NM et al.. Mitochondrial genome sequencing reveals potential origins of the scabies mite Sarcoptes scabiei infesting two iconic Australian marsupials. BMC Evolutionary Biology. 2017;17:233-242. doi:10.1186/s12862-017-1086-9.

3. Cui YB, Li CP, Wang J, Yang QG, Tian Y. Acaroid mites (Acari: Astigmata) in Chinese medicinal herbs. Ann Trop Med Parasitol. 2003;97:865-873. doi:10.1179/000349803225002651.

4. Fang W, Cui YB. A survey of stored product mites of traditional Chinese medicinal materials. Pan-Pac Entomol. 2009;85:174-181. doi:10.3956/2007-42.1.

5. Weigert A et al.. Evolution of mitochondrial gene order in Annelida. Mol. Evol. 2016;94, 196-206. doi:10.1016/j.ympev.2015.08.008.

6. Masta SE, Boore JL. Parallel Evolution of Truncated Transfer RNA Genes in Arachnid Mitochondrial Genomes. Molecular Biology and Evolution. 2008;25(5):949-959. doi:10.1093/molbev/msn051.

7. Zhang D, Szymura JM, Hewitt GM. Evolution and structural conservation of the control region of insect mitochondrial DNA. J Mol Evol. 1995;40:382-391. doi:10.1007/BF00164024.

8. Simon S, Hadrys, H. A comparative analysis of complete mitochondrial genomes among Hexapoda. Mol. Phylogenet. Evol. 2013;69:393-403. doi:10.1016/j.ympev.2013.03.033.

9. Koblmüller S et al.. Whole mitochondrial genomes illuminate ancient intercontinental dispersals of grey wolves (Canis lupus). J. Biogeogr. 2016;43:17281738.doi:1111/jbi.12765.

10. Shalabi M. A. et al.. Comparative phylogeography of the endemic Japanese weasel (Mustela itatsi) and the continental Siberian weasel (Mustela sibirica) revealed by complete mitochondrial genome sequences. Biol. J. Linn. Soc. 2016;120:333-348. doi:10.1111/bij.12891.

11. Li WN, Xue XF. Mitochondrial genome reorganization provides insights into the relationship between oribatid mites and astigmatid mites (Acari: Sarcoptiformes: Oribatida). Zoological Journal of the Linnean Society. 2019;187(3):585-598. doi:10.1093/zoolinnean/zlz044.

12. Jühling F, Pütz J, Bernt M, Donath A, Middendorf M, Florentz C, Stadler PF. Improved systematic tRNA gene annotation allows new insights into the evolution of mitochondrial tRNA structures and into the mechanisms of mitochondrial genome rearrangements. Nucleic Acids Research. 2011;40(7):28332845. doi:10.1093/nar/gkr1131.

13. Schattner P, Brooks AN, Lowe TM. The tRNAscan-SE, snoscan and snoGPS web servers for the detection of tRNAs and snoRNAs. Nucleic Acids Res. 2005;33:W686-9. doi:10.1093/nar/gki366.

14. Laslett D, Canback B. ARWEN: a program to detect tRNA genes in metazoan mitochondrial nucleotide sequences. Bioinformatics. 2008;24:172-175. doi:10.1093/bioinformatics/btm573.

15. Bernt M, Donath A, Jühling F, Externbrink F, Florentz C, Fritzsch G, Pütz J, Middendorf M, Stadler PF. MITOS: Improved de novo metazoan mitochondrial genome annotation. Mol Phylogenet Evol. 2013;69:313-319. doi:10.1016/j.ympev.2012.08.023.

16. Dermauw W, Van Leeuwen T, Vanholme B, Tirry L. The complete mitochondrial genome of the house dust mite, Dermatophagoides pteronyssinus (Trouessart): a novel gene arrangement among arthropods. BMC Genomics. 2009;10(1):107. doi:10.1186/1471-2164-10-107.

17. Klimov PB, \& OConnor BM. Improved tRNA prediction in the American house dust mite reveals widespread occurrence of extremely short minimal tRNAs in acariform mites. BMC Genomics. 2009;10(1):598. doi:10.1186/1471-2164-10-598.

18. Xue XF, Deng W, Qu SX, Hong XY, Shao R. The mitochondrial genomes of sarcoptiform mites: are any transfer RNA genes really lost? BMC Genomics. 2018;19:466. doi:10.1186/s12864-018-4868-6.

19. Salinas T, Duby F, Larosa V, Coosemans N, Bonnefoy N, et al.. Co-Evolution of Mitochondrial tRNA Import and Codon Usage Determines Translational Efficiency in the Green Alga Chlamydomonas. PLoS Genet. 2012;8(9):e1002946. doi:10.1371/journal.pgen.1002946.

20. Yang B, Li C. Characterization of the complete mitochondrial genome of the storage mite pest Tyrophagus longior (Gervais) (Acari: acaridae) and comparative mitogenomic analysis of four acarid mites. Gene. 2016;576:807-19. doi:10.1016/j.gene.2015.11.012.

21. Que S, Zou Z, Xin T, Xia B. Complete mitochondrial genome of the mold mite,

Tyrophagus putrescentiae (Acari: acaridae). Mitochondrial DNA. 2014;27:688-9. doi:10.3109/19401736.2014.913144.

22. Fang WX, Dong FY, Sun ET, Tao DD, Wang Y, Xu JY, Ye CJ. De novo sequence of the mitochondrial genome of Tyrophagus putrescentiae (Acari: Sarcoptiformes) including 22 tRNA sequences and the largest non-coding region. Experimental and Applied Acarology. 2020;80:521-530. doi:10.1007/s10493-020-00477-3.

23. Esteban R, Doña J, Vierna J, Vizcaíno A, Serrano D, Jovani R. The complete mitochondrial genome of the feather mite Trouessartia rubecula Jablonska, 1968 (Astigmata: Analgoidea: Trouessartiidae), Mitochondrial DNA Part B. 2018;3(2):652-654. doi:10.1080/23802359.2018.1476072.

24. Sun ET, Li CP, Li S, Gu S, Nie LW. Complete mitochondrial genome of Caloglyphus berlesei (Acaridae: Astigmata): the first representative of the genus Caloglyphus. Journal of Stored Products Research. 2014a;59:282-284. doi:10.1016/j.jspr.2014.06.010.

Page 9/25 
25. Sun ET, Li CP, Nie LW, Jiang YX. The complete mitochondrial genome of the brown leg mite, Aleuroglyphus ovatus (Acari: Sarcoptiformes): evaluation of largest non-coding region and unique tRNAs. Experimental and Applied Acarology. 2014b;64:141-157. doi:10.1007/s10493-014-9816-9.

26. Gu, XB., Liu, GH., Song, HQ. et al.The complete mitochondrial genome of the scab mite Psoroptes cuniculi(Arthropoda: Arachnida) provides insights into Acari phylogeny. Parasites Vectors. 2014;7, doi:10.1186/1756-3305-7-340.

27. Lee CC, Wang J. The complete mitochondrial genome of Histiostoma blomquisti (Acari: Histiostomatidae). Mitochondrial DNA Part B. 2016;1:671-673. doi:10.1080/23802359.2016.1219633.

28. Satoh TP, Miya M, Mabuchi K, Nishida M. Structure and variation of the mitochondrial genome of fishes. BMC Genomics. 2016;17:719. doi:10.1186/s12864-016-3054-y.

29. Ji HS, Xu XF, Jin XF, Yin H, Luo JX, Liu GY, Zhao Q, Chen Z, Bu WJ, Gao S. Using high-resolution annotation of insect mitochondrial DNA to decipher tandem repeats in the control region. RNA Biology. 2019;16(6):830-837. doi:10.1080/15476286.2019.1591035.

30. Zhang DX, Hewitt GM. Insect mitochondrial control region: a review of its structure, evolution and usefulness in evolutionary studies. Biochem Syst Ecol. 1997;25:99-120. doi:10.1371/journal.pone.0029419.

31. Schäffer S, Koblmuller S, Klymiuk I, Thallinger GG. The mitochondrial genome of the oribatid mite Paraleius leontonychus: new insights into tRNA evolution and phylogenetic relationships in acariform mites. Scientific Reports. 2018;8:7558. doi:10.1038/s41598-018-25981-w.

32. Staton JL, Daehler LL, and Brown WM. Mitochondrial gene arrangement of the horseshoe crab Limulus polyphemus L: Conservation of major features among arthropod classes. Molecular Biology and Evolution. 1997;14(8): 867-874. doi:10.1093/oxfordjournals.molbev.a025828.

33. Boore JL, and Brown WM. Complete DNA sequence of the mitochondrial genome of the black chiton, Katharina tunicata. Genetics. 1994;138(2):423-443.

34. Boore JL, and Brown WM. Complete sequence of the mitochondrial DNA of the annelid worm Lumbricus terrestris. Genetics. 1995;141(1):305-319.

35. Tyagi K, Chakraborty R, Cameron SL et al.. Rearrangement and evolution of mitochondrial genomes in Thysanoptera (Insecta). Sci Rep. $2020 ; 10: 695$. doi:10.1038/s41598-020-57705-4.

36. Li W, Shao R, Zhang Q, Deng W, Xue X. Mitochondrial genome reorganization characterizes various lineages of mesostigmatid mites (Acari: Parasitiformes). Zoologica Scripta. 2019;48:679-689. doi:10.1111/zsc.12369.

37. Murillo P, Klimov P, Hubert J et al.. Investigating species boundaries using DNA and morphology in the mite Tyrophagus curvipenis (Acari: Acaridae), an emerging invasive pest, with a molecular phylogeny of the genus Tyrophagus. Exp Appl Acarol. 2018;75:167-189. doi:10.1007/s10493-018-0256-9.

38. Dabert M, Witalinski W, Kazmierski A, Olszanowski Z, Dabert J. Molecular phylogeny of acariform mites (Acari, Arachnida): strong conflict between phylogenetic signal and long-branch attraction artifacts. Molecular Phylogenetics and Evolution. 2010; 56:222-241. doi:10.1016/j.ympev.2009.12.020.

39. Klimov PB, O'Connor BM, Chetverikov PE, Bolton SJ, Pepato AR, Mortazavi AL, Tolstikov AV, Bauchan GR, Ochoa R. Comprehensive phylogeny of acariform mites (Acariformes) provides insights on the origin of the four-legged mites (Eriophyoidea), a long branch. Molecular Phylogenetics and Evolution. 2018;119:105-117. doi:10.1016/j.ympev.2017.10.017.

40. Aspaly G, Stejskal V, Peka'r S, Hubert J. Temperature-dependent population growth of three species of stored product mites (Acari: Acaridida). Exp Appl Acarol. 2007;42(1):37-46. doi:10.1007/s10493-007-9074-1.

41. Hughes AM. The mites of stored food and houses. 2nd ed. Min Agric Fish Food Tech Bull 9. London: HM Stationery office; 1976. p. $150-156$.

42. Webster LMI, Thomas RH, \& McCormack GP. Molecular systematics of Acarus siro s. lat., a complex of stored food pests. Molecular Phylogenetics and Evolution. 2004;32(3):817-822. doi:10.1016/j.ympev.2004.04.005.

43. Zhang S, Alvarado AS. Planarian High Molecular Weight DNA Isolation by Spooling. Methods Mol Biol. 2018;1774:277-284. doi:10.1007/978-1-49397802-1_8.

44. Minoche AE, Dohm JC \& Heinz H. Evaluation of genomic high-throughput sequencing data generated on illumina HiSeq and genome analyzer systems. Genomics Biological. 2011;12:112. doi:10.1186/gb-2011-12-11-r112.

45. Kumar S, Stecher G, Li M, Knyaz C, Tamura K. MEGA X: Molecular Evolutionary Genetics Analysis across Computing Platforms. Molecular Biology and Evolution. 2018; 35(6):1547-1549. doi:10.1093/molbev/msy096.

46. Altschul SF, Madden TL, Schäffer AA, Zhang J, Zhang Z, Miller W, Lipman DJ. Gapped BLAST and PSI-BLAST: a new generation of protein database search programs. Nucleic Acids Research. 1997;25:3389-3402. doi:10.1093/nar/25.17.3389.

47. Zuker M. Mfold web server for nucleic acid folding and hybridization prediction. Nucleic Acids Res. 2003;31:3406-3415. doi:10.1093/nar/gkg595.

48. Larkin MA, Blackshields G, Brown N, Chenna R, McGettigan PA, McWilliam H, Valentin F, Wallace IM, Wilm A, Lopez R, Thompson JD, Gibson TJ, Higgins DG. Clustal W and Clustal X v.2.0. Bioinformatics. 2007;23(21):2947-2948. doi:10.1093/bioinformatics/btm404.

49. Lorenz R, Bernhart SH, Siederdissen CHZ, Tafer H, Flamm C, Stadler PF, Hofacker IL. ViennaRNA Package 2.0. Algorithms Mol Biol. 2011;6:26. doi:10.1186/1748-7188-6-26.

50. Katoh K, Standley DM. MAFFT multiple sequence alignment software version 7: improvements in performance and usability. Molecular Biology and Evolution. 2013;30:772-780. doi:10.1093/molbev/mst010.

51. Castresana J. Selection of conserved blocks from multiple alignments for their use in phylogenetic analysis. Molecular Biology and Evolution. 2000;17:540-552. doi:10.1093/oxfordjournals.molbev.a026334.

52. Lanfear R, Frandsen PB, Wright AM, Senfeld T, Calcott B. PartitionFinder 2: new methods for selecting partitioned models of evolution for molecular and morphological phylogenetic analyses. Molecular Biology and Evolution. 2017;34(3):772-773. doi:10.1093/molbev/msw260.

53. Ronquist F, Teslenko M, van der Mark P, Ayres DL, Darling A, Hohna S, Larget B, Liu L, Suchard MA, Huelsenbeck JP. MrBayes 3.2: efficient Bayesian phylogenetic inference and model choice across a large model space. Systematic Biology. 2012;61:539-542. doi:10.1093/sysbio/sys029.

Page 10/25 
54. Alfaro ME. Bayes or bootstrap? A simulation study comparing the performance of Bayesian Markov chain Monte Carlo sampling and bootstrapping in assessing phylogenetic confidence. Molecular Biology and Evolution. 2003;20:255-266. doi:10.1093/molbev/msg028.

55. Stamatakis A. RAxML-VI-HPC: maximum likelihood-based phylogenetic analyses with thousands of taxa and mixed models. Bioinformatics. 2006;22: 2688-2690. doi:10.1093/bioinformatics/btl446.

56. Hillis DM \& Bull JJ. An empirical test of bootstrapping as a method for assessing confidence in phylogenetic analysis. Systematic Biology. 1993;42:182192. doi: $10.2307 / 2992540$.

57. Domes K, Maraun M, Scheu S, Cameron SL. The complete mitochondrial genome of the sexual oribatid mite Steganacarus magnus: genome rearrangements and loss of tRNAs. BMC Genom. 2008;9:532. doi:10.1186/1471-2164-9-532.

58. ZHAO YN, LI CP. Sequencing and analysis of the complete mitochondrial genome of Carpoglyphus lactis (Acari: Carpoglyphidae). Acta Entomologica Sinica. 2020;63(3):354-364. doi:10.16380/j.kcxb.2020.03.012.

59. Han YD, Min GS. Complete mitochondrial genome of the feather mite Ardeacarus ardeae (Acari, Sarcoptiformes, Pterolichidae). Mitochondrial DNA Part B. 2017;2:41-42. doi:10.1080/23802359.2017.1289345.

60. Mofiz E, Seemann T, Bahlo M, Holt D, Currie BJ, Fischer K, Papenfuss AT. Mitochondrial genome sequence of the scabies mite provides insight into the genetic diversity of individual scabies infections. PLoS Neglected Tropical Diseases. 2016;10:e0004384. doi:10.1371/journal.pntd.0004384.

\section{Additional Files}

Additional file 1: Figure S1 Predicted secondary structures of the $22 \mathrm{mt}$ tRNAs of Lepidoglyphus destructor. Bars indicate Watson-Crick base pairings; dots and circles represent GU pairs and mismatched pairs, respectively.

Additional file 2: Figure S2 Predicted secondary structures of the $22 \mathrm{mt}$ tRNAs of Gohieria fusca. Bars indicate Watson-Crick base pairings; dots and circles represent GU pairs and mismatched pairs, respectively.

Additional file 3: Table S1 Mitochondrial genome organization of Histiostoma blomquisti and Histiostoma feroniarum.

\section{Tables}

Table 1 Mitochondrial genome organization of Lepidoglyphus destructor and Gohieria fusca. Int = intergenic nucleotides; negative numbers indicate overlapping nucleotides between adjacent genes. 


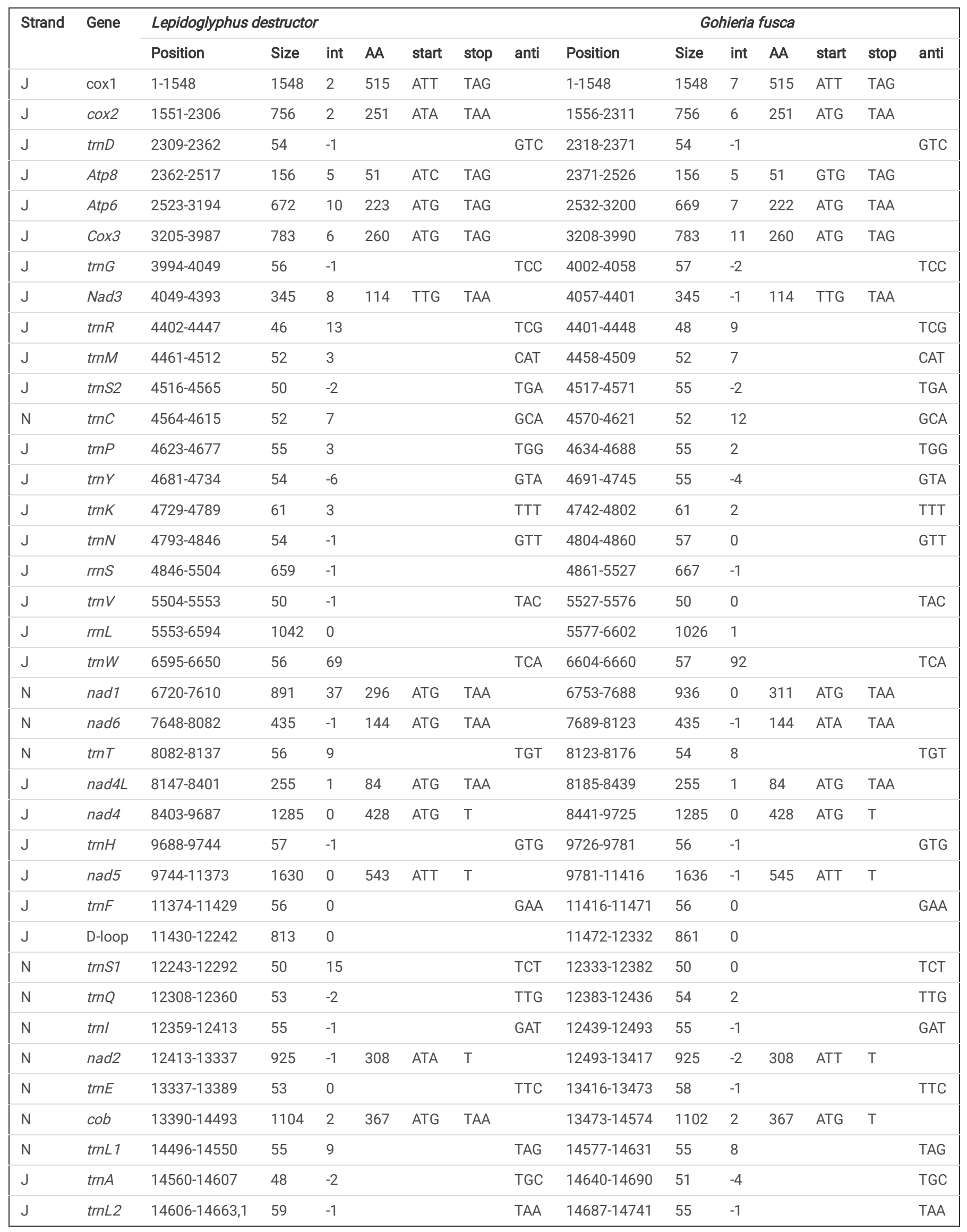

Table 2. Distribution of NCRs in the astigmatid mites mitochondrial genomes. 


\begin{tabular}{|c|c|c|c|c|c|c|c|c|c|}
\hline \multirow[t]{2}{*}{ Species } & \multicolumn{6}{|c|}{ Conservative non-coding region } & \multicolumn{3}{|c|}{ Nonconservative noncoding region } \\
\hline & length & position & AT(\%) & length & position & AT(\%) & length & position & AT(\%) \\
\hline Lepidoglyphus destructor & $813^{*}$ & $\operatorname{trnF-trnS1}$ & $68.4 \%$ & 69 & trnW-nad1 & $55.1 \%$ & & & \\
\hline Gohieria fusca & $861^{*}$ & $\operatorname{trnF-trnS1}$ & $70.7 \%$ & 92 & trnW-nad1 & $63.0 \%$ & & & \\
\hline Acalvolia sp. & $753^{*}$ & $\operatorname{trnF-trnS1}$ & $76.6 \%$ & $273^{*}$ & trnW-nad1 & $78.8 \%$ & & & \\
\hline Carpoglyphus lactis & $303^{*}$ & trnF-trnS1 & $88.4 \%$ & 66 & $\operatorname{trn} W$-nad1 & $72.7 \%$ & & & \\
\hline Aleuroglyphus ovatus & $378^{*}$ & trnF-trnS1 & $82.5 \%$ & 57 & trnW-nad1 & $75.4 \%$ & & & \\
\hline Caloglyphus berlesei & $341^{*}$ & trnF-trnS1 & $89.4 \%$ & 53 & trnW-nad1 & $71.7 \%$ & & & \\
\hline Rhizoglyphus robini & $319 *$ & $\operatorname{trnF-trnS1}$ & $87.1 \%$ & 53 & trnW-nad1 & $71.7 \%$ & & & \\
\hline Tyrophagus putrescentiae & $245^{\star}$ & $\operatorname{trnF-trnS1}$ & $93.1 \%$ & 53 & trnW-nad1 & $67.9 \%$ & & & \\
\hline Dermatophagoides farinae & $410^{*}$ & $\operatorname{trnF-trnS1}$ & $90.5 \%$ & 46 & $\operatorname{trn} W$-nad1 & $65.2 \%$ & & & \\
\hline Dermatophagoides pteronyssinus & $286^{*}$ & $\operatorname{trnF-trnS1}$ & $91.7 \%$ & 44 & trnW-nad1 & $65.9 \%$ & & & \\
\hline Ardeacarus ardeae & $214^{*}$ & $\operatorname{trnF-trnS1}$ & $91.6 \%$ & 29 & trnW-nad1 & $89.7 \%$ & & & \\
\hline Psoroptes cuniculi & $382^{\star}$ & $\operatorname{trnF-trnS1}$ & $89.8 \%$ & 62 & trnW-nad1 & $72.6 \%$ & & & \\
\hline Sarcoptes scabiei & 76 & $\operatorname{trnF-trnS1}$ & $98.7 \%$ & 62 & trnW-nad1 & $79.0 \%$ & & & \\
\hline Trouessartia rubecula & $301 *$ & trnF-trnS1 & $84.7 \%$ & 56 & trnW-nad1 & $73.5 \%$ & & & \\
\hline Tyrophagus longior & & & & 49 & trnW-nad1 & $73.5 \%$ & 50 & $r r n S-r r n L$ & $90.0 \%$ \\
\hline Histiostoma blomquisti & $624^{\star}$ & $\operatorname{trnF-trnS1}$ & $68.6 \%$ & & & & $1598^{*}$ & $r r n S-t r n V$ & $67.8 \%$ \\
\hline Histiostoma feroniarum & & & & $146^{*}$ & trnW-nad1 & $73.9 \%$ & $143^{*}$ & Nad4-trnH & $81.1 \%$ \\
\hline
\end{tabular}

Note: Non-coding regions marked with a star are assumed to be putative control regions. The data for Trouessartia rubecula, Histiostoma blomquisti, and $H$. feroniarum in the table are after our revision.

Table 3. The alignment of nucleotide sequences of four mitochondrial tRNA genes (trnS2, trnW, trnF, and trnI) in five reported astigmatid species in four different superfamilies. 


\begin{tabular}{|c|c|c|c|c|c|c|c|c|}
\hline Gene & Species & AA-arm & & D-arm & AC-arm & V-loop & T-arm & AA-arm \\
\hline \multirow[t]{5}{*}{$\operatorname{tms2}$} & Ao & GTCTTCTA & TTTT & & GGAACTTTGAAAGTTCT & TTTT & $\underline{\text { AGGGGTTTTCCCCT }}$ & TAGAGAC \\
\hline & Gf & $\underline{\text { GGTCTTT }}$ & ATTATACA & & ITAACTTTGAAAGTTAA & TTT & $\underline{\text { AGGGTTTCCCCT }}$ & AAAGGCT \\
\hline & Df & $\underline{\text { GTCTTTA }}$ & TATCTTG & & ITAATTTTGAAAGITGA & CTTT & $\underline{\text { GCTTTTT }} \underline{\text { AGC }}$ & $\underline{\text { TAAAGAC }}$ \\
\hline & *Hb & $\underline{\text { ITTAGCT }}$ & TTA & & AATTITTTGACCACCIT & C & IATAGCC & AGTTAAA \\
\hline & $\mathrm{Hf}$ & ITTGTCG & TTTTTATAC & & TTAACTTTGAAAGTTTT & GT & ITGGTTTTCÉTAA & TGACTTA \\
\hline \multirow[t]{5}{*}{$\operatorname{tm} W$} & Ao & $\underline{\text { AAGTCTT }}$ & TA & $\frac{\text { GGTTAA-GTGAAAACC }}{\mathrm{G}}$ & TACGTCTTCAAADACGTG & AGATTTTTTGTA & - & ACGGCTT \\
\hline & Gf & $\underline{\text { ATAGCTT }}$ & TA & $\frac{\mathrm{AGTTAATTAC-AAACT}}{\mathrm{A}}$ & TACGTCTTCAAAACGTA & AAATAATC & & AAGCTAT \\
\hline & Df & AAAGCTT & TA & $\begin{array}{l}\text { G } \underline{\text { GTTAAAAATAAAACT }} \\
\end{array}$ & TACGICTTCAAAET $\underline{\text { GTA }}$ & TGATTTC & & AAGCTTT \\
\hline & $\mathrm{Hb}$ & $\underline{\mathrm{ATGGCTT}}$ & TA & $\underset{T}{\mathrm{GGTTA}}$-TAT-AAACT & TACGTCTTCAAAACGTA & AGATTT & & TT $\underline{G C T} \underline{A T}$ \\
\hline & *Hf & ITTAGTT & GA & -TTCAGTAC-GAA A & GGACCTCTCAATAGGAA & $\begin{array}{l}\text { A- } \\
\text { ATTTTCTTTTT }\end{array}$ & & AACTATA \\
\hline \multirow[t]{5}{*}{$\operatorname{tmF}$} & Ao & ATGTTTI & TA & $\frac{\text { GTCCCTT-GAGGGC }}{A T}$ & TAGCTTTGAAGGGGCTA & AAGGCTT & & ATAACAT \\
\hline & Gf & $\underline{\text { TATGCT}} \underline{C T}$ & AA & 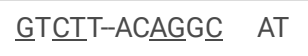 & $\underline{\text { TAGCTTTGAAGGGGCTA }}$ & AAGGTTTC & & AGGCATA \\
\hline & Df & ATGCTTT & TA & GLTIA-AT $\underline{A} G \underline{G} T \quad$ AT & TAGCTTTGAAGGAGCTA & AAGTTTTA & & TGAGCAT \\
\hline & *Hb & $\underline{\text { ATT}} \underline{A T} \underline{\mathrm{CTT} T}$ & TTT & $\begin{array}{l}\text { TATCCTTTTCIT } \\
\text { TC }\end{array}$ & CATAAAGGAATTITTIT & АТTTTСтT & & TAGTGTI \\
\hline & *Hf & TATAAAA & CT & 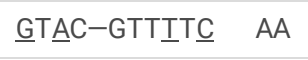 & AACGTAAGAAACTAGCI & ATATGGGG & & AGGTAGG \\
\hline \multirow[t]{5}{*}{$t m l$} & Ao & $\underline{\text { ITAGGCT }}$ & TA & ACCTAAAAGGG $\quad T$ & $\underline{\text { ITACCTTGATGGGGTAA }}$ & ACAAGTAAA & & AGCCTAA \\
\hline & Gf & ITAGGCA & TA & ACC-ACACTTGGG C & ITACCTTGATAGGGTAA & GATTT-AAT & & TGCCTAA \\
\hline & Df & ITAGGCT & $\mathrm{CA}$ & ACC-AAAAAGGA T & ITACCTTGATAGGGTAA & AAATTAAAA & & AGCCTAA \\
\hline & $\mathrm{Hb}$ & ITAAGCT & AA & ACCTAAT-TGGA A & TIATCTTGATAGGATAA & ACACACAG & & AGCTTAA \\
\hline & *Hf & CDAAAGA & G & $\frac{\text { ATT-AAACAAAACAAT }}{\text { AA }}$ & TIACAATAATAAGCTAT & TTATCTT & & IATTTGC \\
\hline
\end{tabular}

Table 4. The alignment of nucleotide sequences of two mitochondrial tRNA genes ( $\operatorname{trn} A$ and $\operatorname{trn} V$ ) in six species: Conserved nucleotides are shaded in gray across these five mites.

\begin{tabular}{|c|c|c|c|c|c|c|c|c|}
\hline Gene & Species & AA-arm & & D-arm & AC-arm & V-loop & T-arm & AA-arm \\
\hline \multirow[t]{6}{*}{$\operatorname{tm} A$} & Ao & -TGGATGG & AGAGAA & & СTTTTTTTGCAGTAAAG & TCA- & -TTTTTAA & -ССAACCTT \\
\hline & $\mathrm{cb}$ & -TGGATGG & AAAGTA & & $\underline{\text { CTTTTTTTGCACGAAAG }}$ & TCT- & -T-TAGAA & -ССАACCTT \\
\hline & $\mathrm{Rr}$ & -TGGATGG & AAAGTA & & $\underline{\text { CTTTTTTTGCACGAAAG }}$ & TC & -T-TTAAAA & -ССААССТT \\
\hline & Df & TIGGAI & AAGAGAGTG & & ACTTTTTTGCACGAAGT & TTTT & AAATCTT & -AACCATT- \\
\hline & AA & $-\mathrm{TGGACAA}$ & TCTTT & & $\underline{\text { ACTTTTTTGCAGGAAGT }}$ & TTT & -TATATA & $\underline{\text {-TTGACCTT }}$ \\
\hline & TR & $-\underline{G G A C A A G}$ & AGAGA & & GTTTTTTTGCATGAAAC & CAA & -TATA-AG & CTTGACCT \\
\hline \multirow[t]{6}{*}{$\operatorname{tm} V$} & Ao & -TAGAGTT & -TAGTATAT & & ITTTGCTTACAACAAAA & -ATTT & TIT-ATT & TACTCTTT \\
\hline & $\mathrm{cb}$ & -TAGAGTT & CTTATAG & - & ITTTGCTTACAACAAAA & -CTT- & TIT-AT & ААСТСТTТ \\
\hline & Rr & -TAGAGTT & -TTTATAG & - & ITTTGCTTACAACAAAA & -СТTCT & TAT-AACTCITTTA & TTCTCTAT \\
\hline & Df & TTTAGAG & TCTTTATTT & - & ITTTGCTTACAACAAAA & AATC & ITT-AA-AA & СТСТTTTС \\
\hline & AA & -TAAGAGT & -TTTAAAAAT & - & ITTTGCTTACAACAAAA & AATT & ITT-AA & СТСТTTAА \\
\hline & TR & -AGAGAAT & -TTGTATT & _ & ITTTGCTTACAACAAAA & AATT & TTITATCT & -CITGIAIT \\
\hline
\end{tabular}

Note: Nucleotides that pair at the arms (acceptor arm, D arm, anticodon arm, and T arm) are underlined. Sequences of anticodons are in boldface. Aleuroglyphus ovatus (Ao), Caloglyphus berlesei (Cb), Rhizoglyphus robini (Rr), Dermatophagoides farinae (Df), Ardeacarus ardeae (AA), and Trouessartia rubecula (TR) in our study. 
Table 5 The primers used for the amplification of Gohieria fusca and Lepidoglyphus destructor mitochondrial genomes, with the size of each fragment that was amplified in bp.

\begin{tabular}{|llll|}
\hline Specimen & Primer name & Original & sequence Size fragment (bp) \\
\cline { 2 - 3 } G. fusca & Gf-CR-F & GCTTTGAAGGGGCTAAAGGT & 852 \\
\cline { 2 - 3 } & Gf-CR-R & TCTAGGTGCAACAACCAAAG & \\
\hline \multirow{2}{*}{ L. destructor } & Ld-CR-F & TGAAGGGGCTAAAGGTTGCC & \multirow{2}{*}{962} \\
\cline { 2 - 3 } & Ld-CR-R & ACCGGATAGGGTACACCTTG & \\
\hline
\end{tabular}

Table 6 Mitochondrial genomes employed in this study.

\begin{tabular}{|c|c|c|c|c|c|c|}
\hline Cohort & Superfamily & Family & Species & GenBank ID & Size(bp) & Reference \\
\hline Mixonomatides & Phthiracaroidea & Phthiracaridae & Steganacarus magnus & EU935607 & 13818 & Domes et al. (2008) [57] \\
\hline Brachypylina & Oripodoidea & Scheloribatidae & Paraleius leontonychus & LT984407 & 14186 & Schäffer et al. (2018) [31] \\
\hline \multirow[t]{17}{*}{ Astigmatina } & Acaroidea & Acaridae & Aleuroglyphus ovatus & KC700022 & 14328 & Sun et al. (2014b) [25] \\
\hline & & & Caloglyphus berlesei & KF499016 & 14273 & Sun et al. (2014a) [24] \\
\hline & & & Rhizoglyphus robini & MF596168 & 14244 & Xue et al. (2018) [18] \\
\hline & & & Tyrophagus longior & KR869095 & 13271 & Yang \& Li (2016) [20] \\
\hline & & & Tyrophagus putrescentiae & MK_393792 & 14156 & Fang et al. (2020) [22] \\
\hline & Analgoidea & Pyroglyphidae & Dermatophagoides farinae & NC_013184 & 14266 & $\begin{array}{l}\text { Klimov \& O'Connor (2009) } \\
\text { [17] }\end{array}$ \\
\hline & & & $\begin{array}{l}\text { Dermatophagoides } \\
\text { pteronyssinus }\end{array}$ & EU884425 & 14203 & Dermauw et al. (2009) [16] \\
\hline & & Trouessartiidae & Trouessartia rubecula & MH208456 & 14125 & Esteban et al. (2018) [23] \\
\hline & Hemisarcoptoidea & Winterschmidtiidae & Acalvolia sp. & МH921997 & 14711 & Li \& Xue (2019) [11] \\
\hline & & Carpoglyphidae & Carpoglyphus lactis & MN073839 & 14060 & Zhao \& Li (2020) [58] \\
\hline & Histiostomatoidea & Histiostomatidae & Histiostoma blomquisti & KX452726 & 15892 & Lee \& Wang (2016)[27] \\
\hline & & & Histiostoma feroniarum & MF596167 & 13896 & Xue et al. (2018) [18] \\
\hline & Pterolichoidea & Pterolichidae & Ardeacarus ardeae & KY352304 & 14069 & Han \& Min (2017) [59] \\
\hline & Sarcoptoidea & Psoroptidae & Psoroptes cuniculi & KJ957822 & 14247 & Gu et al. (2014) [26] \\
\hline & & Sarcoptidae & Sarcoptes scabiei & CM003133 & 13667 & Mofiz et al. (2016) [60] \\
\hline & Glycyphagoidea & Glycyphagidae & Lepidoglyphus destructor & MT075728 & 14663 & This study \\
\hline & & & Gohieria fusca & MN608156 & 14741 & This study \\
\hline
\end{tabular}

\section{Figures}




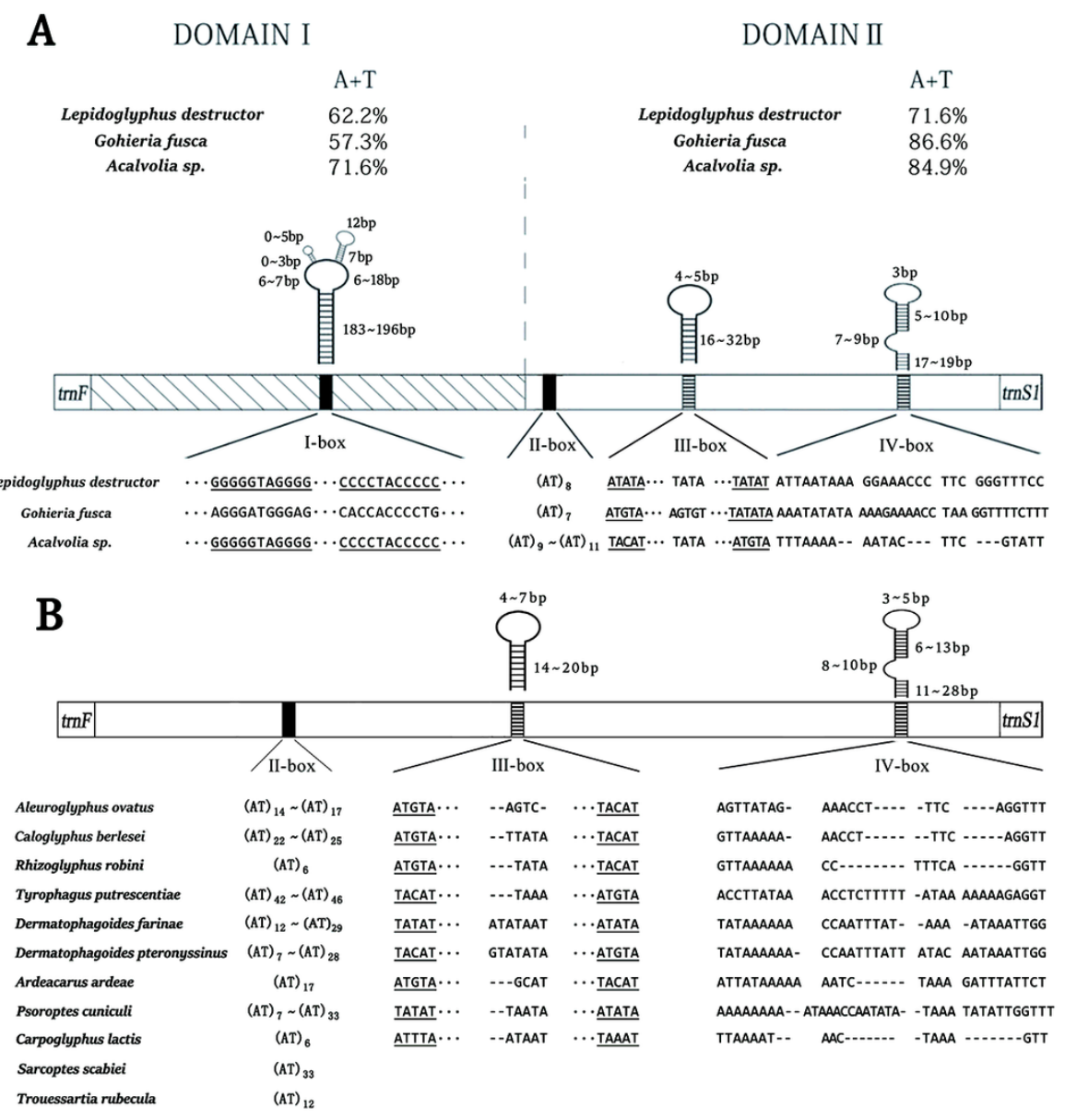

\section{Figure 1}

Conserved sequence blocks and secondary structures of the largest non-coding region in astigmatid mites. (A) Mapped on L. destructor, G. fusca, and Acalvolia sp. The domain I (striped box) and domain II (white box) are marked. The conserved sequences in domain I and the conserved palindromic sequences in domain II are shown in underlined letters. The A+T content of two domains is indicated. (B) Mapped on Aleuroglyphus ovatus, Caloglyphus berlesei, Rhizoglyphus robini, Tyrophagus putrescentiae, Dermatophagoides pteronyssinus, D. farinae, Psoroptes cuniculi, Ardeacarus ardeae, Carpoglyphus lactis, Sarcoptes scabiei, and Trouessartia rubecula (after revision). The conserved palindromic sequences are shown in underlined letters. Accession numbers of the analyzed sequences are reported in Table 6. 


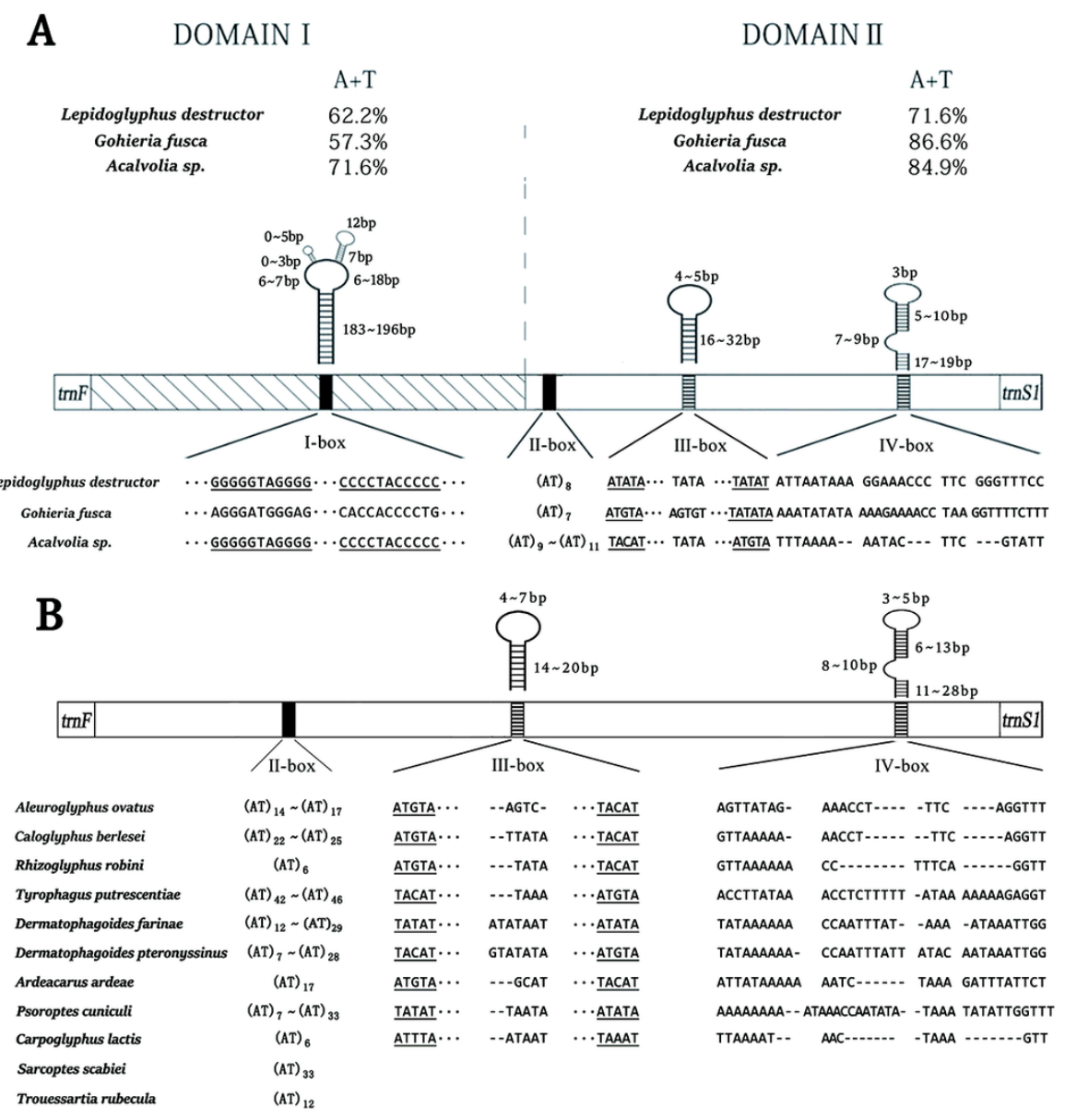

\section{Figure 1}

Conserved sequence blocks and secondary structures of the largest non-coding region in astigmatid mites. (A) Mapped on L. destructor, G. fusca, and Acalvolia sp. The domain I (striped box) and domain II (white box) are marked. The conserved sequences in domain I and the conserved palindromic sequences in domain II are shown in underlined letters. The A+T content of two domains is indicated. (B) Mapped on Aleuroglyphus ovatus, Caloglyphus berlesei, Rhizoglyphus robini, Tyrophagus putrescentiae, Dermatophagoides pteronyssinus, D. farinae, Psoroptes cuniculi, Ardeacarus ardeae, Carpoglyphus lactis, Sarcoptes scabiei, and Trouessartia rubecula (after revision). The conserved palindromic sequences are shown in underlined letters. Accession numbers of the analyzed sequences are reported in Table 6. 


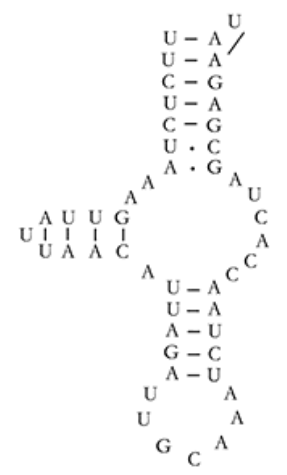

$\mathrm{Hb} \operatorname{trnC}$

MFE $=99992.00$

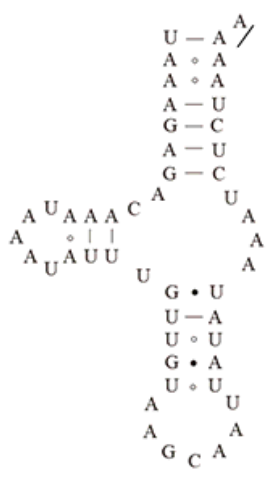

${ }^{*} \mathrm{Hf} \operatorname{trn} C$

MFE $=6.50$

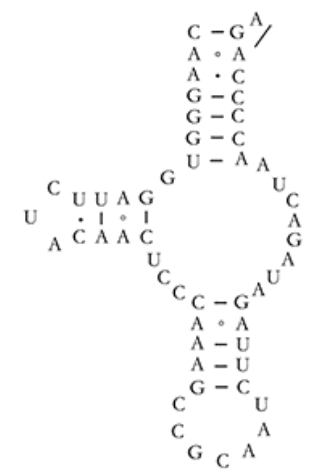

*Hb trnC

MFE $=-4.80$

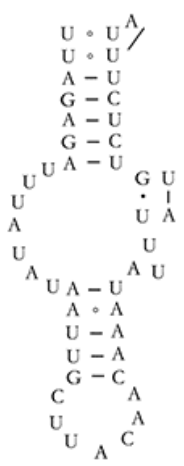

Hf $\operatorname{trn} V$

MFE $=99997.00$

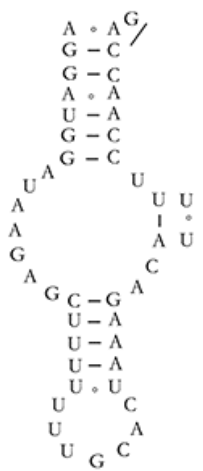

$\mathrm{Hb} \operatorname{trn} A$

MFE $=99991.80$

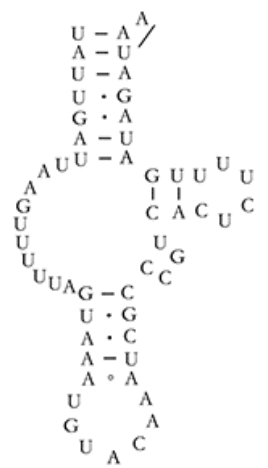

*Hf trnV

MFE $=6.90$

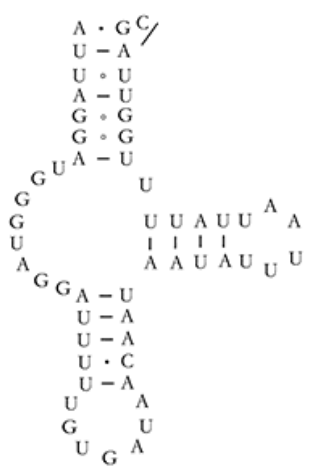

*Hb trnA

MFE $=9.20$

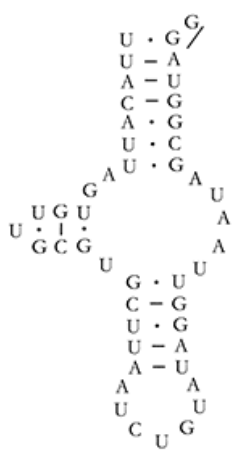

Hf trnQ

MFE $=99998.10$

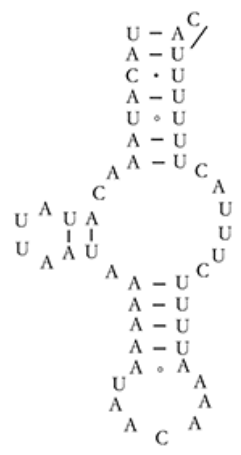

Hf $\operatorname{trn} C$

MFE $=7.00$

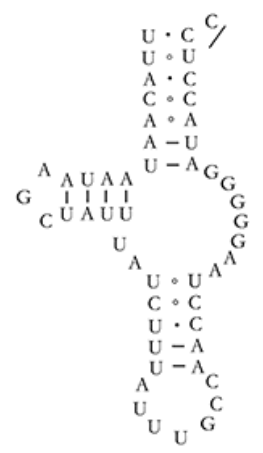

*Hf trnQ

MFE $=17.40$

\section{Figure 2}

Secondary structures of trnC and trnA for Histiostoma blomquisti and trnC, trnV, and trnQ for Histiostoma feroniarum in our study. 


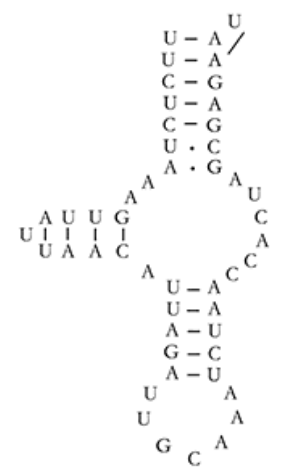

$\mathrm{Hb} \operatorname{trnC}$

MFE $=99992.00$

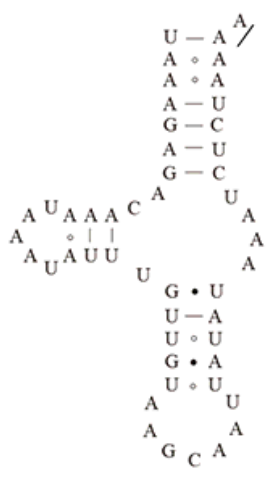

${ }^{*} \mathrm{Hf} \operatorname{trn} C$

MFE $=6.50$

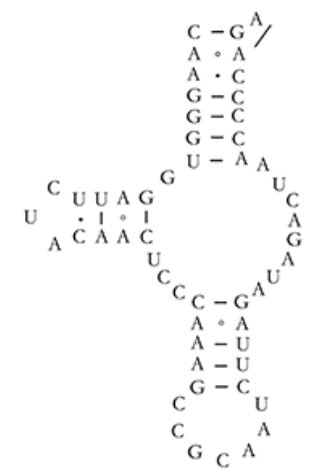

*Hb trnC

MFE $=-4.80$

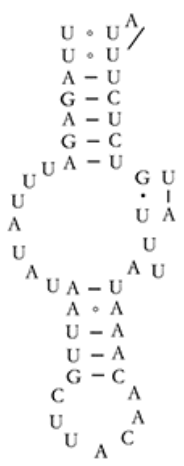

Hf $\operatorname{trn} V$

MFE $=99997.00$

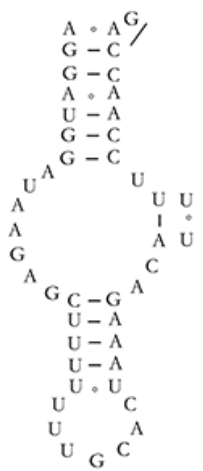

$\mathrm{Hb} \operatorname{trn} A$

MFE $=99991.80$

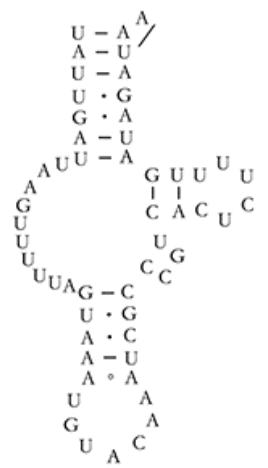

*Hf trnV

MFE $=6.90$

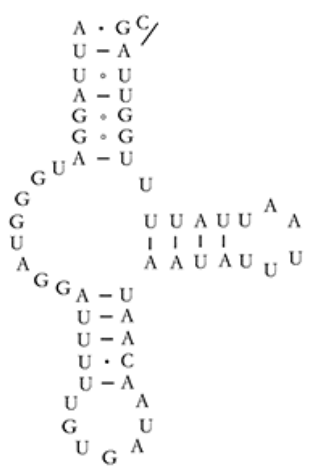

*Hb trnA

MFE $=9.20$

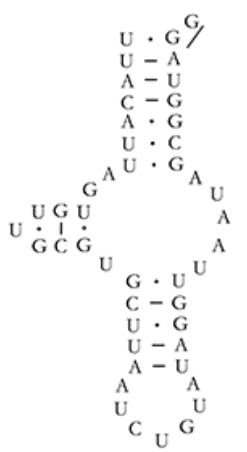

Hf trnQ

MFE $=99998.10$

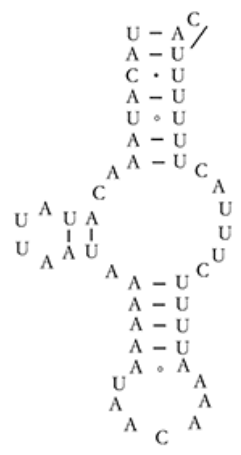

Hf $\operatorname{trn} C$

MFE $=7.00$

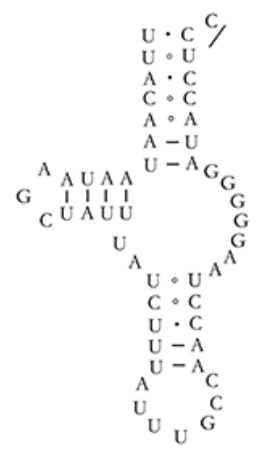

*Hf trnQ

MFE $=17.40$

\section{Figure 2}

Secondary structures of trnC and trnA for Histiostoma blomquisti and trnC, trnV, and trnQ for Histiostoma feroniarum in our study. 


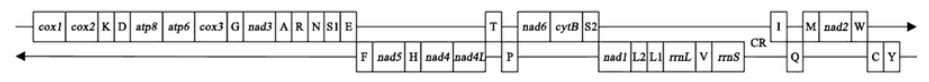

Type I: The possible common ancestor of Astigmatid mites

*Lepidoglyphus destructor (Glycyphagoidea), ${ }^{*}$ Gohieria fusca (Glycyphagoidea)

Aleuroglyphus ovatus (Acaroidea), Caloglyphus berlesei (Acaroidea), Rhizoglyphus robini (Acaroidea),

Tyrophagus putrescentiae (Acaroidea)

*Trouessartia rubecula (Acaroidea), Dermatophagoides pteronyssinus (Analgoidea), Dermatophagoides

farinae (Analgoidea)

Psoroptes cuniculi (Sarcoptoidea), Sarcoptes scabiei (Sarcoptoidea), Ardeacarus ardeae (Pterolichoidea),

Carpoglyphus lacti (Hemisarcoptoidea)

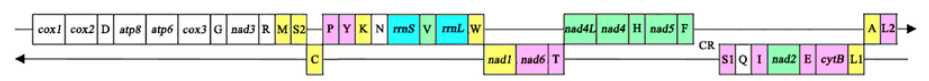

Type II: Acalvolia sp. (Hemisarcoptoidea)

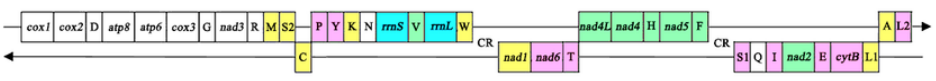

Type III: *Histiostoma blomquisti (Histiostomatoidea)

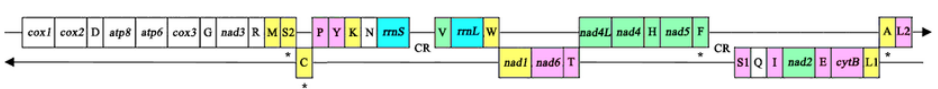

Type IV: *Histiostoma feroniarum (Histiostomatoidea)

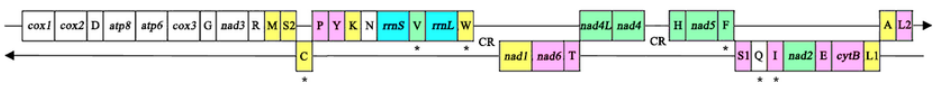

${ }^{4}$ Histiostoma blomquisti (Histiostomatoidea)

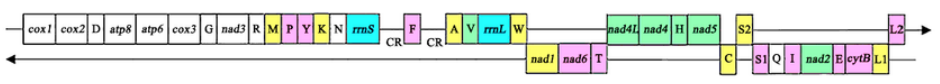

${ }^{\Delta}$ Histiostoma feroniarum (Histiostomatoidea)

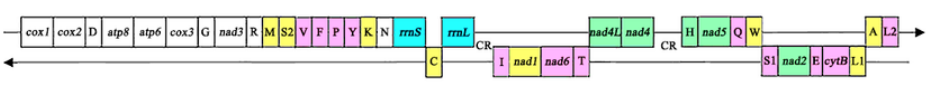

${ }^{\Delta}$ Trouessartia rubecula (Analgoidea)

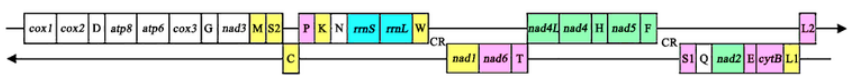

\section{Figure 3}

Mitochondrial gene arrangements in the sarcoptiform mites. The arrow pointing to the right represents the (+)-strand, and the arrow to the left the (-)-strand. Translocated or inverted genes are color-coded (green: inversion and translocation; pink: translocation; yellow: inversion). rRNA genes are in blue. The possible common ancestor among astigmatid mites is found in different genera and families. Species marked with a star: tRNAs reannotated in our study. Species marked with a triangle: the gene order in previous studies. 


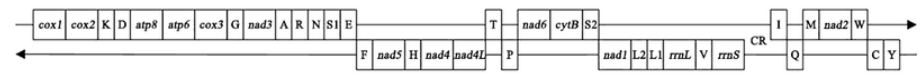

Type I: The possible common ancestor of Astigmatid mites

*Lepidoglyphus destructor (Glycyphagoidea), *Gohieria fusca (Glycyphagoidea)

Aleuroglyphus ovatus (Acaroidea), Caloglyphus berlesei (Acaroidea), Rhizoglyphus robini (Acaroidea),

Tyrophagus putrescentiae (Acaroidea)

*Trouessartia rubecula (Acaroidea), Dermatophagoides pteronyssinus (Analgoidea), Dermatophagoides

farinae (Analgoidea)

Psoroptes cuniculi (Sarcoptoidea), Sarcoptes scabiei (Sarcoptoidea), Ardeacarus ardeae (Pterolichoidea),

Carpoglyphus lacti (Hemisarcoptoidea)

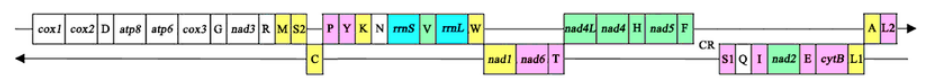

Type II: Acalvolia sp. (Hemisarcoptoidea)

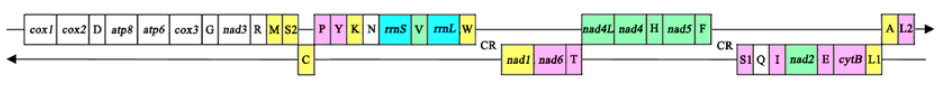

Type III: *Histiostoma blomquisti (Histiostomatoidea)

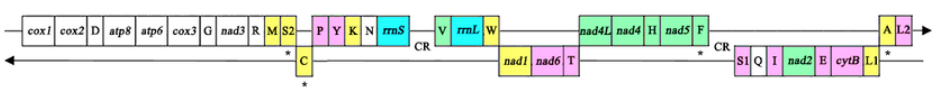

Type IV: *Histiostoma feroniarum (Histiostomatoidea)

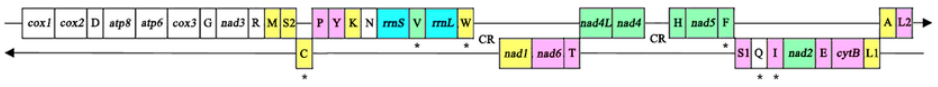

${ }^{4}$ Histiostoma blomquisti (Histiostomatoidea)

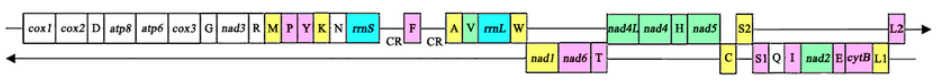

${ }^{4}$ Histiostoma feroniarum (Histiostomatoidea)

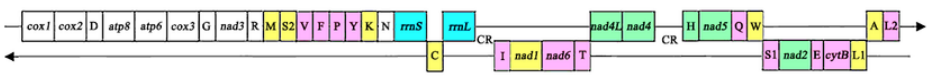

${ }^{\Delta}$ Trouessartia rubecula (Analgoidea)

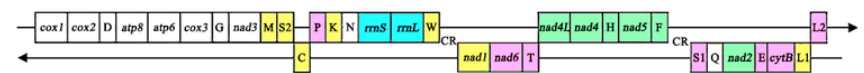

\section{Figure 3}

Mitochondrial gene arrangements in the sarcoptiform mites. The arrow pointing to the right represents the (+)-strand, and the arrow to the left the (-)-strand. Translocated or inverted genes are color-coded (green: inversion and translocation; pink: translocation; yellow: inversion). rRNA genes are in blue. The possible common ancestor among astigmatid mites is found in different genera and families. Species marked with a star: tRNAs reannotated in our study. Species marked with a triangle: the gene order in previous studies.

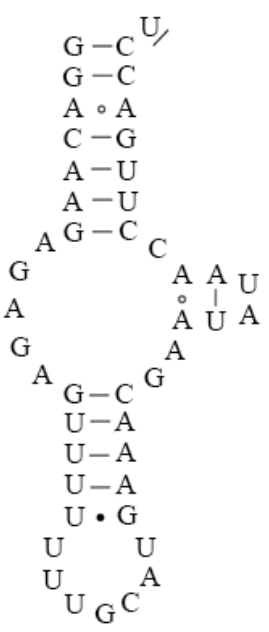

$\operatorname{trn} A$

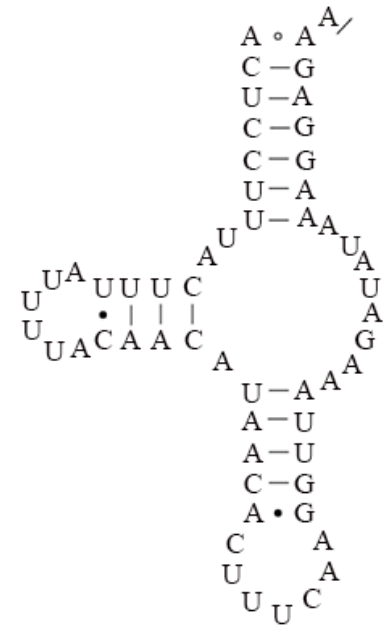

$\operatorname{trn} E$

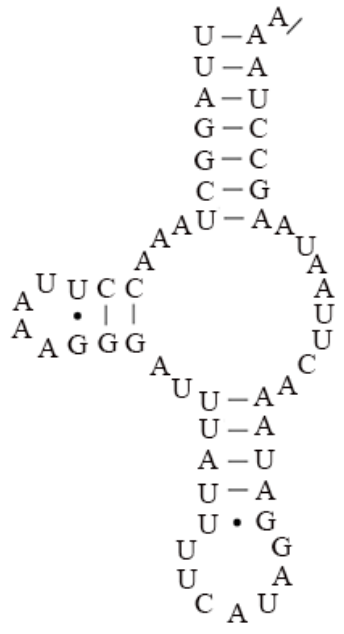

trnI

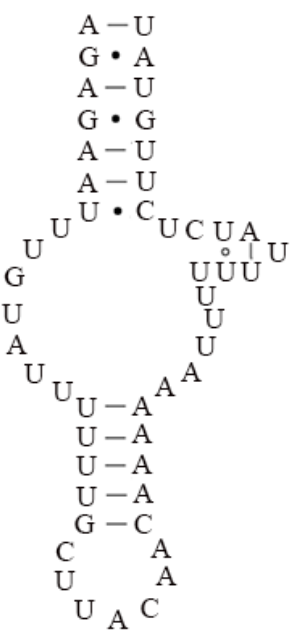

$\operatorname{trn} V$

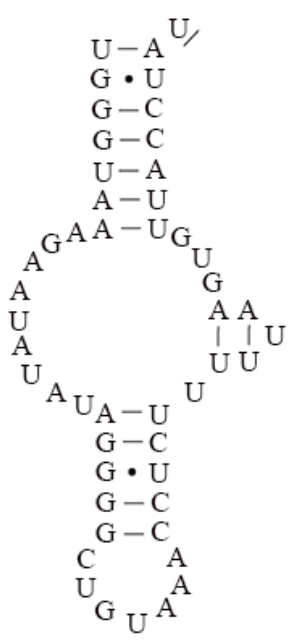

$\operatorname{trn} Y$ 
Figure 4

Secondary structures of trnA, trnE, trnl, trnV, and trnY for Trouessartia rubecula in our study.

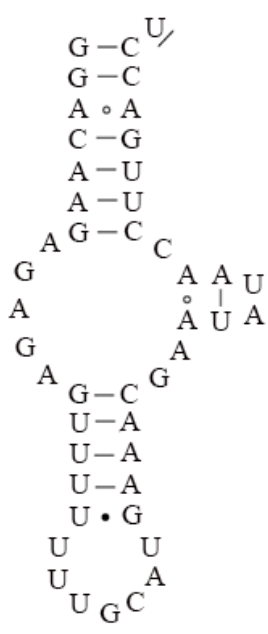

$\operatorname{trn} A$

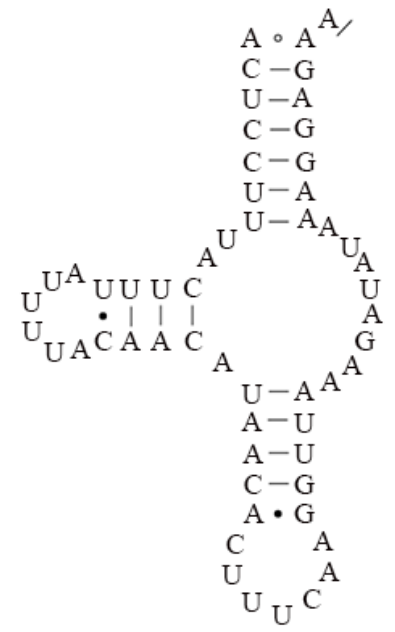

$\operatorname{trn} E$

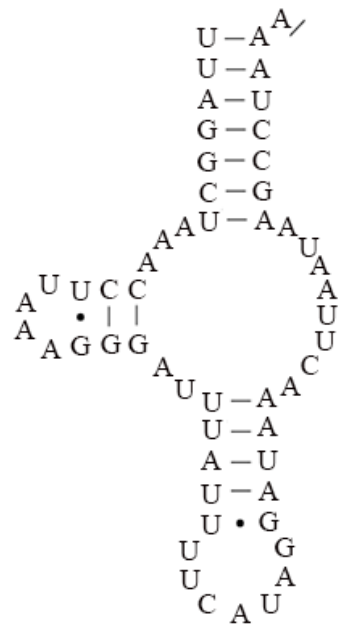

$\operatorname{trnI}$

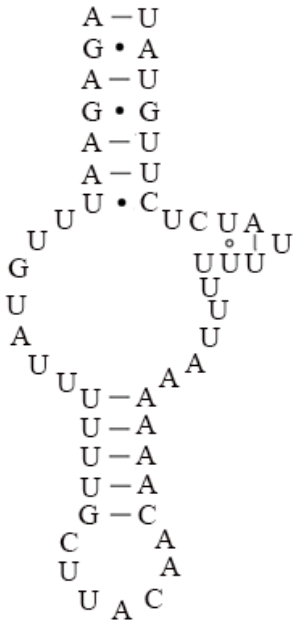

$\operatorname{trn} V$

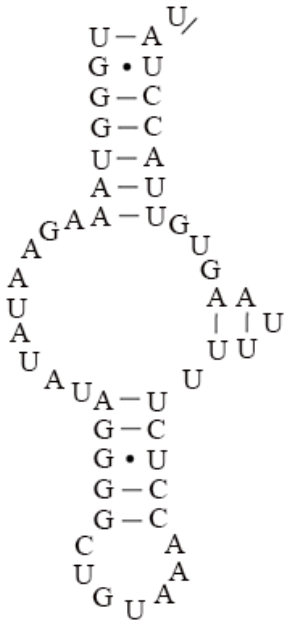

$\operatorname{trn} Y$

$\mathrm{MFE}=-5.00$

$\mathrm{MFE}=-\mathbf{8 . 2 0}$

$\mathrm{MFE}=-8.10$

$\mathrm{MFE}=-12.40$

\section{Figure 4}

Secondary structures of trnA, trnE, trnl, trnV, and trnY for Trouessartia rubecula in our study.
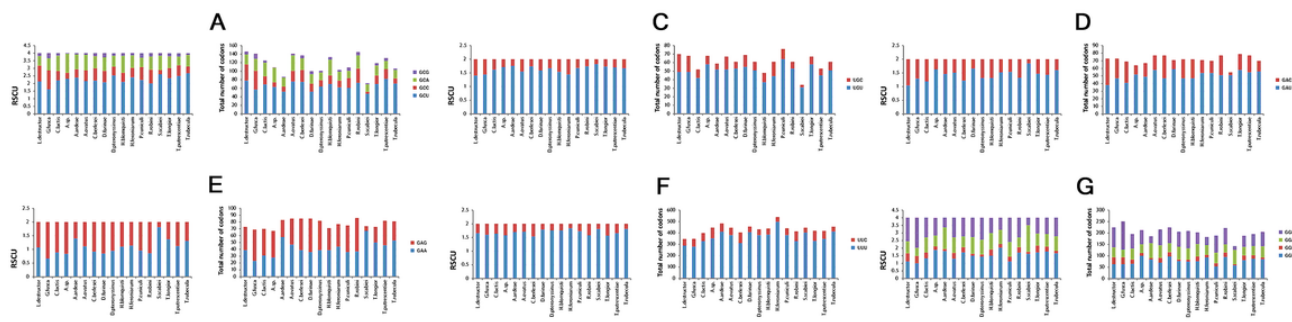

G
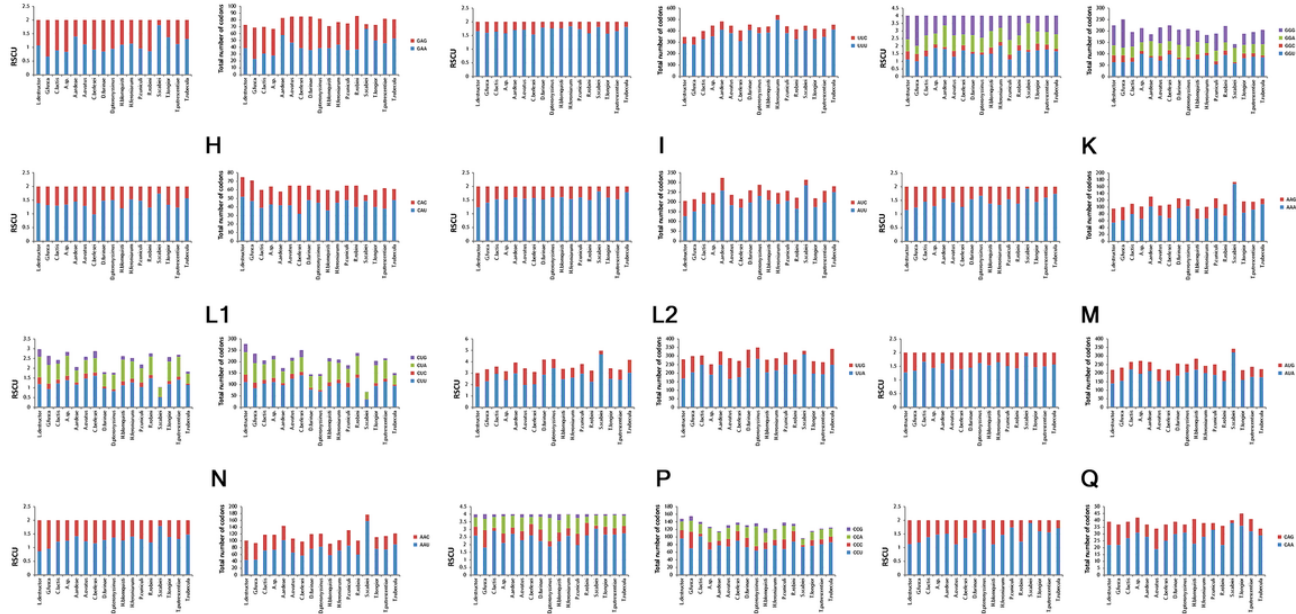

Q
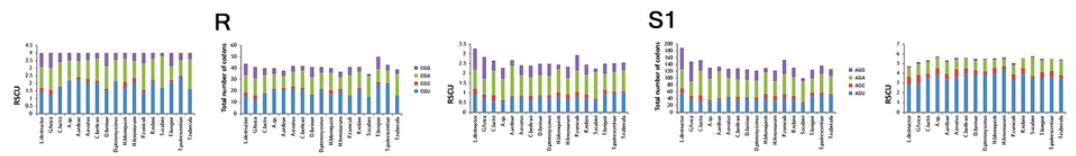

S2
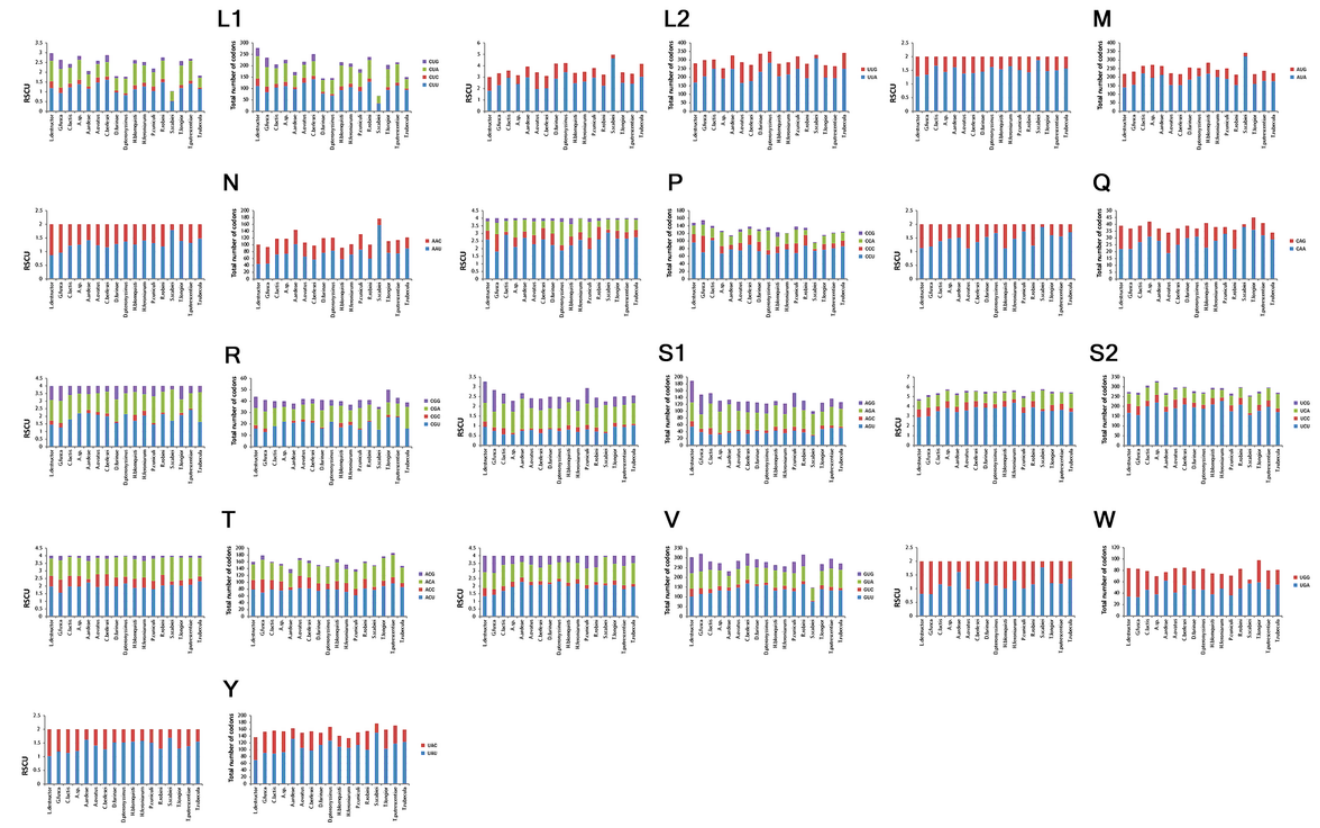
Figure 5

Relative synonymous codon usage (RSCU) and codon numbers of 22 amino acids (a, c, d, e, f, g, h, i, k, I1, I2, m, n, p, q, r, s1, s2, t, v, w, and y) in the mitochondrial $(\mathrm{mt})$ genomes of astigmatid mites. The X-axis indicates the astigmatid mites; the Y-axis indicates the RSCU or total number of codons. The blue column indicates the codons that are complimentary to the anticodons of their corresponding mt tRNA. The red, green and purple columns indicate the imperfect, synonymous codons to the anticodons of their corresponding mt tRNA genes.
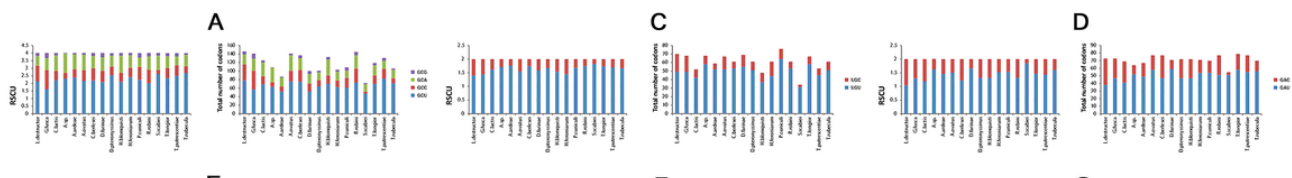

E

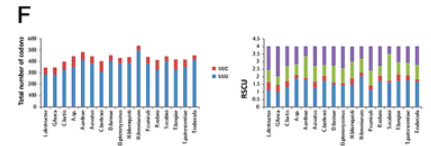

G
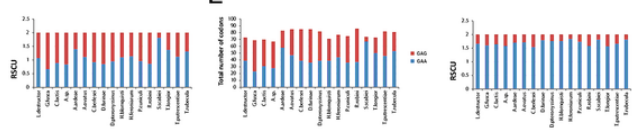

|W||||||||||||||||| :-

K

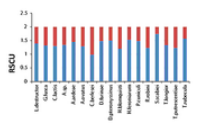

$\mathrm{H}$

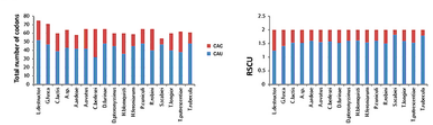

I
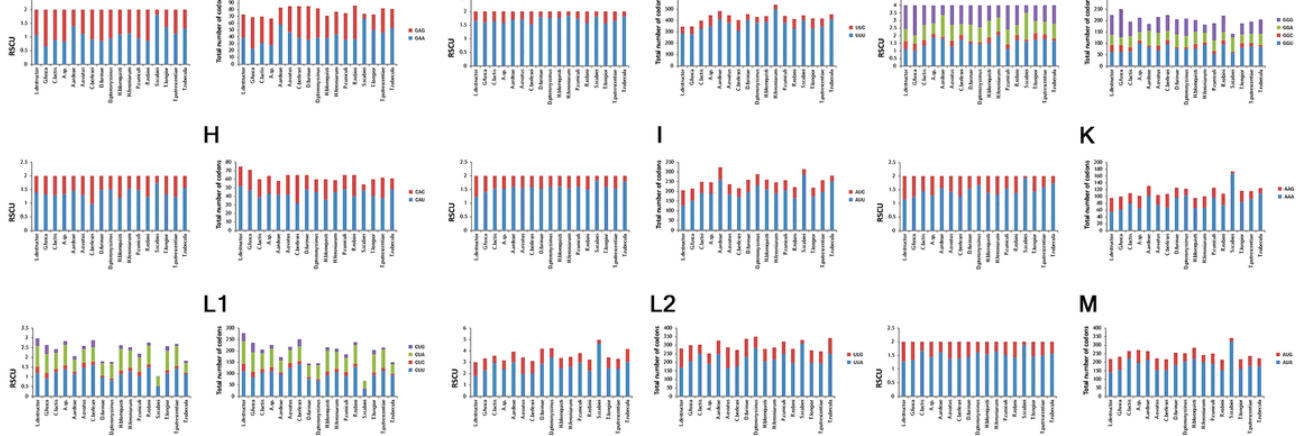

L2
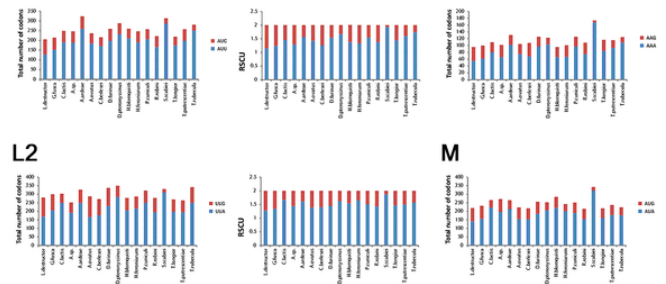

N

$\mathrm{P}$

Q
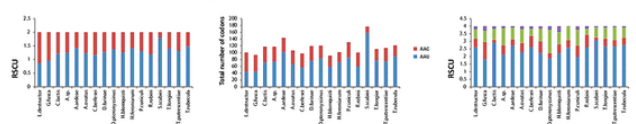

:
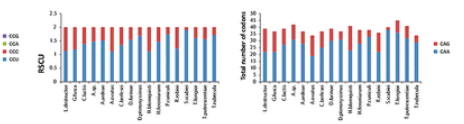

R

S1

S2

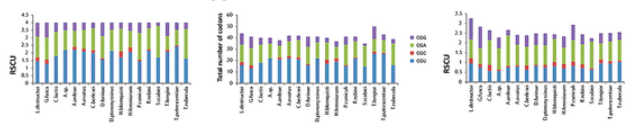

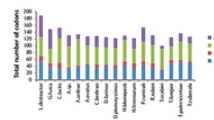

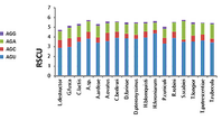

$\mathbf{T}$
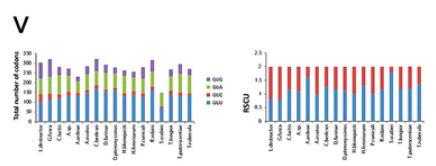

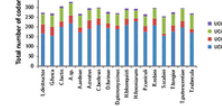
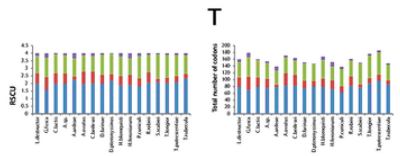

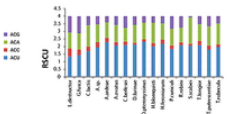

Y
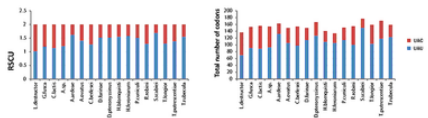

\section{Figure 5}

Relative synonymous codon usage (RSCU) and codon numbers of 22 amino acids (a, c, d, e, f, g, h, i, k, I1, I2, m, n, p, q, r, s1, s2, t, v, w, and y) in the

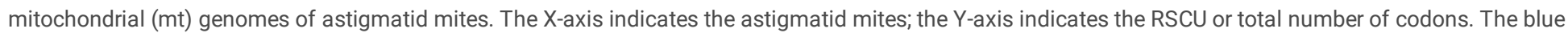

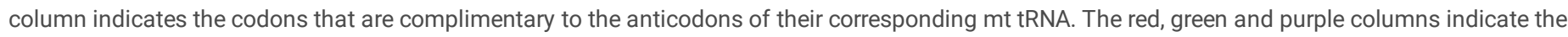
imperfect, synonymous codons to the anticodons of their corresponding mt tRNA genes. 


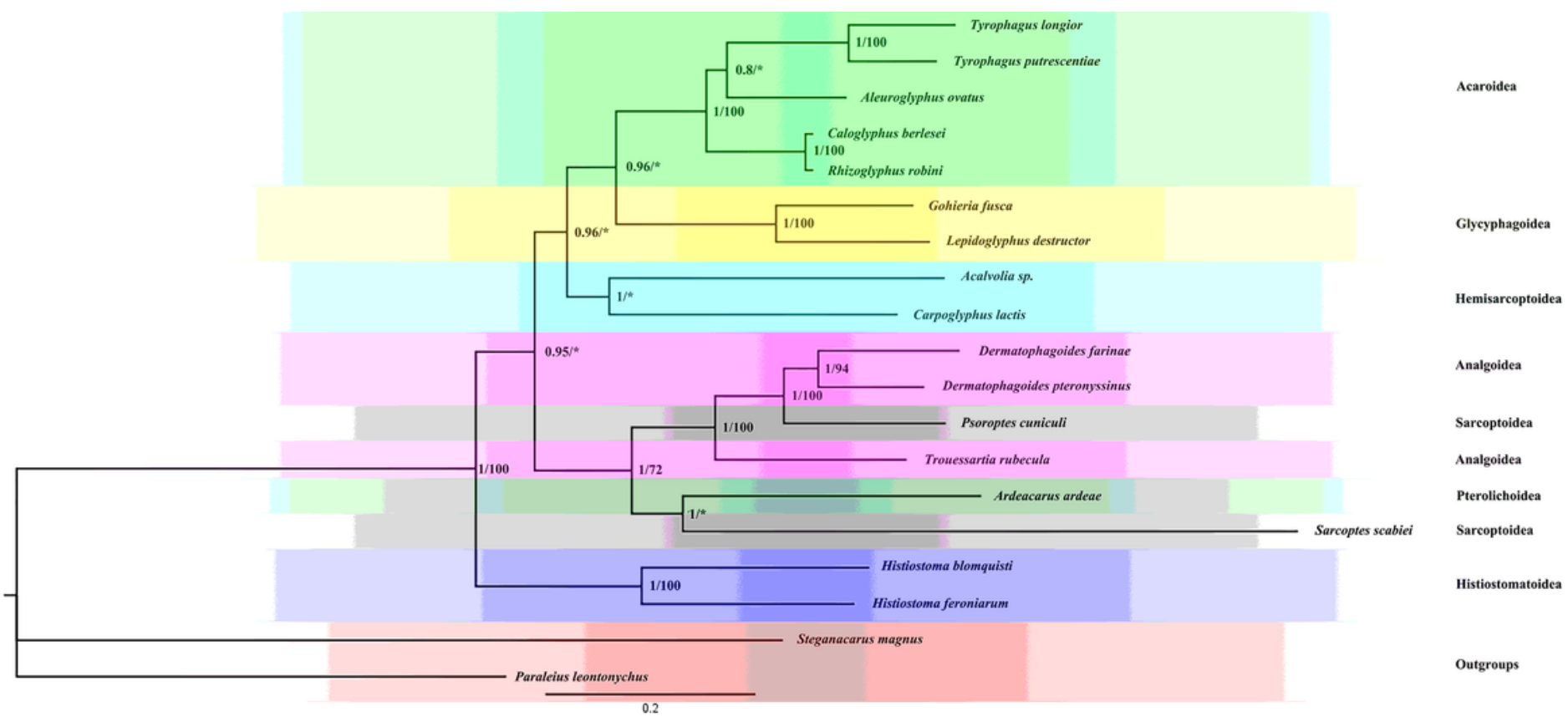

\section{Figure 6}

Phylogenetic tree inferred from mitochondrial genome sequences using maximum likelihood and Bayesian methods. Branch lengths presented here follow the Bayesian methods analysis. Node numbers indicate Bayesian posterior probabilities (BPP) and maximum likelihood bootstrap proportions (BSP). * indicates clades with BSP $<70 \%$.

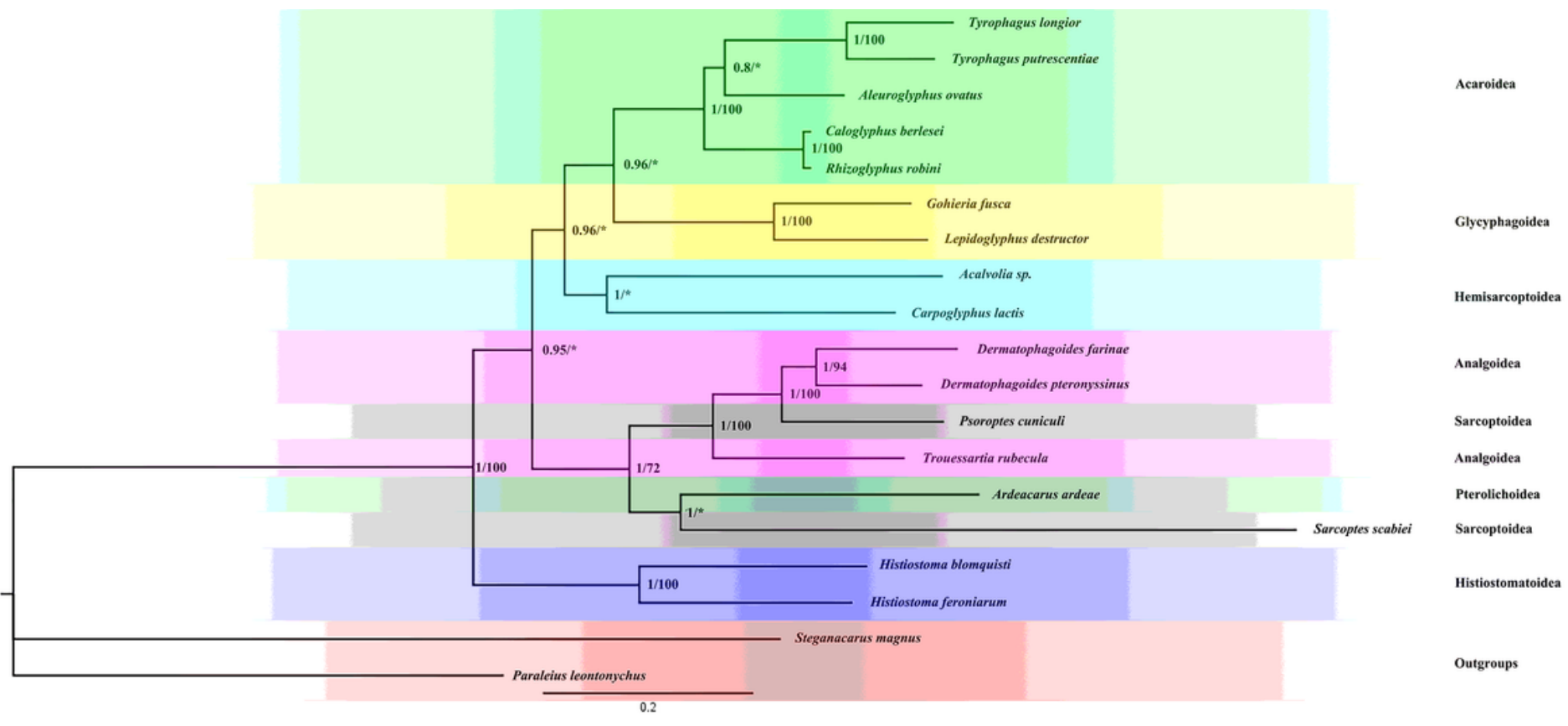

\section{Figure 6}

Phylogenetic tree inferred from mitochondrial genome sequences using maximum likelihood and Bayesian methods. Branch lengths presented here follow the Bayesian methods analysis. Node numbers indicate Bayesian posterior probabilities (BPP) and maximum likelihood bootstrap proportions (BSP). * indicates clades with BSP $<70 \%$.

\section{Supplementary Files}

This is a list of supplementary files associated with this preprint. Click to download.

- Tables1.docx

- Tables1.docx

- OnlineFigureS1.Png 
- OnlineFigureS1.Png

- OnlineFigures2.Png

- OnlineFigures2.Png

Page 25/25 